\title{
LA FORMACIÓN DEL ESTADO EN NICARAGUA Y COSTA RICA EN PERSPECTIVA COMPARADA: SIGLOS XIX-XX
}

\author{
THE FORMATION OF NICARAGUAN AND COSTA RICAN STATES \\ IN THE NINETEENTH AND TWENTIETH CENTURIES: \\ A COMPARATIVE APPROACH
}

Victor H. Acuña Ortega

Recibido: 23/07/2018 - Aceptado: 07/09/2018

\begin{abstract}
Resumen
Este ensayo de periodización, síntesis e interpretación históricas analiza la formación del Estado en Nicaragua y Costa Rica en los siglos XIX y XX, desde una perspectiva comparativa. Postula que los procesos de centralización estatal son resultado, en primera y en última instancia, de conflictos y negociaciones entre múltiples actores en la esfera política y en la arena militar. Su tesis principal es que, en la larga duración, la formación del Estado en Costa Rica ha sido un proceso acumulativo; mientras que en Nicaragua se trata de un proceso abortado repetidas veces. Se proponen algunas hipótesis para explicar esa trayectoria divergente de estos Estados, en el marco de sus historias conectadas o entrecruzadas.
\end{abstract}

Palabras clave: Estado, Nación, Régimen político, Nicaragua, Costa Rica, Historia comparada.

\begin{abstract}
This essay proposes a comparative analysis of the formation of Nicaraguan and Costa Rican states during the Nineteenth and Twentieth centuries and it singles out the main historical periods of these processes. It puts forward that state formation is above all the result of conflicts and negotiations among different actors in the polity and in the military arena. Its main thesis is that, in the longue durée, the Costa Rican state formation has been cumulative and, on the contrary, in Nicaragua this process has been, again and again, incomplete. It elaborates some hypothesis in order to explain that opposite evolution of these states in the context of their connected or crossed histories.
\end{abstract}

Keywords: State, Nation, Political Regime, Nicaragua, Costa Rica, Comparative History. 
Este proceso se llegó a conocer como la 'piñata de Daniel', una oportunidad para funcionarios del gobierno de todos los niveles para apropiarse de los bienes del Estado.

Algunos Ministerios -Cancillería, Interior, Economía, Industria y Comercio-fueron totalmente saqueados; en algunos casos, altos oficiales del gobierno nuevo de Chamorro llegaban a sus oficinas sin escritorios y sillas.

Dirk Kruijt. Guerrilla: guerra y paz en Centroamérica (2009).

En la Casa de Gobierno había asesores panameños ayudándonos a organizar la administración; un día se apareció Marcel Salamín llevándome una máquina eléctrica como regalo del general Omar Torrijos, junto con cajas de lápices, libretas e instrumentos de oficina comprados en las tiendas de los turcos de Panamá.

Sergio Ramírez. Adiós muchachos. Una memoria de la revolución sandinista (1999).

Al ver a los jefes [Tomás Martínez y Máximo Jerez] con su vestido común marchando al Templo entre una valla de soldados a gran distancia el uno del otro; al oír el Te Deum más triste que quizá se ha cantado en nuestras funciones cívicas; al ver que los pocos concurrentes se reian de aquel espectáculo que les parecía ridículo, todos presagiaban que la Junta no podría dar un paso, teniendo dos cabezas tan opuestas, y que su vida iba a ser efímera, concluyendo luego con un pleito entre los mandatarios. Mellizo, gemelo, chacho, con estos y otros apodos mentaban a aquel Gobierno, de quien esperaban nada bueno y mucho malo; pero en fin, vueltos del acto religioso a la Casa de Gobierno, iniciaron sus tareas, y icosa risible! para ello el General Martínez sacó unos reales de su bolsillo para comprar papel, tinta y otros útiles de oficina; y lo mismo hicieron otros mientras no se dispuso de un producto de la Hacienda Pública.

Jerónimo Pérez.

Biografía del Gral. Tomás Martínez (1879).

Costa Rica, el solar amado en que lloraron y rieron nuestros abuelos, el pedazo de suelo limpido y glorioso en que van a gozar y a sufrir nuestros remotos descendientes.

Julio Acosta, Presidente de Costa Rica Informe Anual al Congreso, 8 de mayo de 1924. 
La República fortalece hoy con este acto de suyo trascendente, su tradicional credo democrático, en que hay alternabilidad en el Gobierno, ya que únicamente la nación debe ser inmutable, como es su honor intangible y sus glorias imperecederas.

León Cortés, Presidente de Costa Rica, Informe Anual al Congreso, 8 de mayo de 1940.

\section{Consideraciones generales}

A partir de la década de 1990, las ciencias sociales y la historia en y sobre Centroamérica empezaron a estudiar en una perspectiva moderna los procesos de formación de las naciones (Palmer, 1990; Taracena y Piel, 1995). También datan de aquellos años los trabajos que, sobre todo desde la sociología política y desde la ciencia política, intentaron dar cuenta de la evolución de los regímenes políticos en la región, centrados en la divergencia o disonancia entre Costa Rica y los otros países. ${ }^{1}$ Curiosamente, el interés por los problemas del autoritarismo, la democracia y, lo que acababa de acontecer, la revolución, y por la cuestión de las naciones, el nacionalismo y los recién descubiertos problemas étnicos, no se acompañó de una preocupación similar por los fenómenos de construcción y formación del Estado, a pesar de que hubo algunos intentos al respecto. ${ }^{2}$

La carencia de investigaciones ha llegado hasta el presente, ya que a la par de la explosión de los estudios sobre etnicidad y nación y de los análisis de los regímenes políticos, los Estados centroamericanos aún son poco estudiados. El asunto parece paradójico porque fueron precisamente esos Estados los que lograron o no lograron la invención de naciones en el istmo desde mediados del siglo XIX, además, fue a partir de dichos Estados que se edificaron los regímenes políticos que han caracterizado a los distintos países hasta el presente.

Este artículo es un intento por llamar la atención sobre el asunto de los procesos de formación de los Estados centroamericanos y es una invitación a que se emprendan estudios empíricamente fundados y en una perspectiva histórica sobre tales procesos. La propuesta se justifica en el sentido de señalar que se debe analizar el vínculo entre el proceso de centralización política y de monopolización de los medios de coerción, por parte de un conjunto de personas y de instituciones, y los efectos que tal proceso producen sobre los mecanismos y modalidades, mediante los cuales se definen los procedimientos de acceso al poder y los recursos para mantenerse en este, y sobre la forma en que ese Estado en formación se dota o no se dota de una legitimidad política e ideológica, principalmente por medio de la invención de una comunidad nacional.

El proceso de centralización política también puede ser sintomático respecto a las características y comportamientos en el plano sociopolítico de las élites o clases dominantes y de sus relaciones de conflicto y cooperación con las clases populares y subalternas. En este sentido, se trata de suspender, al menos provisoriamente, 
los análisis que se han hecho inspirados en los trabajos de Barrington Moore, los cuales correlacionan regímenes políticos y estructuras agrarias (Moore, 1966); ${ }^{3}$ con el fin de concentrarse en una cuestión, mucho menos compleja, pero muy poco estudiada, que puede ser formulada con la siguiente pregunta: ¿de qué se habla cuando se analizan los Estados en Centroamérica en el periodo que va desde la independencia hasta la crisis de 1930 o hasta el fin de la Segunda Guerra Mundial? La pregunta implícitamente afirma que fue durante ese periodo cuando todos los Estados centroamericanos adquirieron sus atributos básicos. También subyace en ella la suposición de que dicho proceso de formación del Estado tuvo sus propios ritmos según los países.

En esta perspectiva, se propone la hipótesis metodológica de que puede ser muy provechoso, para valorar la necesidad de emprender estudios sobre la formación de los Estados en Centroamérica, realizar una historia comparada y entrecruzada o conectada de los procesos de formación del Estado en Nicaragua y Costa Rica en la larga duración. ${ }^{4}$ En términos de sus particularidades, la comparación entre ambos Estados puede ser interesante en la medida en que muchos aspectos los contrastan, a pesar de haber surgido, al final de la época colonial, de una misma matriz político-administrativa y eclesiástica, es decir, la Diputación Provincial y el obispado y de haber compartido una historia común en el espacio centroamericano hasta el presente. ${ }^{5}$ Se trata de Estados vecinos con múltiples entrecruces de sus procesos históricos, por ejemplo, los procesos migratorios, los exilios y las disputas fronterizas. ${ }^{6}$ En el istmo, Costa Rica y Guatemala se anticiparon en el proceso de centralización política. Costa Rica avanzó más temprano y rápido en el proceso de invención de la nación; en fin, Costa Rica se ha distinguido en términos considerados excepcionales como el país que consolidó un régimen político democrático, moderno y consistente desde mediados del siglo XX.7

En contraste, Nicaragua fue el único país en el istmo en el cual triunfó, para luego fracasar, una revolución popular con un proyecto socialista o socializante. Este país padeció la dictadura más prolongada de la región y ha tenido históricamente mayores dificultades para alcanzar y consolidar, en forma irreversible, su centralización política. Asimismo, Nicaragua fue el único país centroamericano, no se incluye a Panamá en esta definición de Centroamérica, que fue un protectorado de Estados Unidos, en el periodo 1912-1933. En fin, el contraste se puede llevar al plano económico, ya que históricamente Costa Rica ha sido un país mucho más próspero que Nicaragua y los otros países de la región.

Esta hipótesis metodológica se complementa con otra hipótesis de igual naturaleza en relación con las élites o clases dominantes, la cual puede formularse en los siguientes términos: independientemente de los condicionamientos estructurales que establecen las bases materiales de las clases dominantes, es decir, sus regímenes o modalidades de acumulación, es en la esfera de lo político, que incluye lo militar o los diversos usos de la violencia, y en interacciones entre sus grupos constitutivos o fracciones y en relaciones de confrontación y cooperación o colaboración, volunta- 
ria o no, con las clases subalternas y populares, que logran o no logran centralizar el poder, es decir, formar un Estado y establecer tal o cual régimen político. Así, se sostiene que de una estructura agraria determinada o de cierta modalidad de acumulación de capital no se deriva nada en forma automática en el plano de los procesos de construcción de Estado, invención de la nación e institucionalización de tal o cual régimen político. Por el contrario, todos estos son procesos contingentes, es decir, sus desenlaces acontecen en la esfera de lo político, mediante la competencia política y la confrontación armada.

La construcción del Estado es un asunto de correlaciones de fuerzas entre actores políticos y sociales, tanto de los arriba como de los de abajo, por eso tiene siempre que ver con luchas de clases o de otro tipo de actores, vinculados por lealtades horizontales, étnicas o de género. La preocupación, en suma, no es estudiar los regímenes políticos, autoritarios o democráticos, sino analizar el proceso de construcción del Estado como entramado de relaciones y como sistema institucional. La idea es que la construcción del Estado y la invención de la nación constituyen el marco estructural en el cual evolucionan los regímenes políticos.

Al respecto, es de suma utilidad la diferenciación que desarrolla Guillermo O’Donnell entre régimen político y Estado. Así, por Estado este autor entiende:

Un conjunto de instituciones y de relaciones sociales (la mayor parte de estas sancionadas por el sistema legal de ese estado) que normalmente penetra y controla el territorio y los habitantes que ese conjunto pretende delimitar geográficamente. Esas instituciones tienen último recurso [sic], para efectivizar las decisiones que toman, a la supremacía en el control de medios de coerción física que algunas agencias especializadas del mismo estado normalmente ejercen sobre aquel territorio (O’Donnell 2).

Mientras que define régimen político en los siguientes términos:

Por régimen entiendo los patrones, formales e informales, y explícitos e implícitos, que determinan los canales de acceso a las principales posiciones de gobierno, las características de los actores que son admitidos y excluidos de tal acceso, los recursos y las estrategias permitidos para lograrlo, y las instituciones a través de las cuales ese acceso ocurre y, una vez logrado, son tomadas las decisiones gubernamentales (O’Donnell 5).

Como se desprende de estas definiciones, Estado es un concepto más amplio que régimen político, ya que sus dimensiones y competencias abarcan el conjunto de la vida económica, social, política y cultural y es, además, lógica e históricamente anterior al régimen democrático. En palabras de O’Donnell, "el gobierno es una parte fundamental del Estado, su cúpula institucional. Por su parte, el régimen es una mediación entre el Estado y la sociedad" (O’Donnell 6). ${ }^{8}$ De este modo, 
el régimen es solo una de las dimensiones del Estado como entramado de relaciones sociales.

Este ensayo tiene limitaciones muy precisas, las cuales conviene inmediatamente dejar claras: en primer lugar, se trata de un trabajo basado en los estudios existentes; en segundo lugar, son muy pocos los que se ocupan explícitamente sobre la cuestión de la formación del Estado en ambos países; en tercer lugar, por razones conocidas, los trabajos sobre el desarrollo histórico de Costa Rica son más abundantes y de mayor calidad profesional que sus similares en el caso de Nicaragua; en cuarto lugar, las obras que se ocupan explícitamente de la cuestión del Estado se inscriben dentro de marcos categoriales marxistas estructuralistas o de carácter muy dogmático, en boga en las décadas de 1970 y 1980; y por último, para el caso nicaragüense, existen algunos estudios recientes que abordan la cuestión del Estado y del régimen político en una perspectiva más bien de tipo sociocultural o psicosocial, en la cual la existencia material del Estado queda fuera de foco, en oposición al proceso de centralización política tal y como realmente aconteció. ${ }^{9}$

La principal dificultad que enfrenta cualquier intento de análisis de la formación de los Estados en Centroamérica es que la bibliografía disponible es, por un lado, la vieja historia episódica, cuyo interés se centra en el relato de la vida política de los países del istmo y, por otro lado, los trabajos que se realizan desde la ciencia política proponen modelos, tipologías y periodizaciones de los regímenes políticos de la región, con frecuencia basados casi exclusivamente en esa bibliografía añeja. De esta manera, en este artículo se intenta obtener informaciones e interpretaciones en forma oblicua o indirecta, mediante una especie de lectura a contrapelo, de la bibliografía disponible sobre los regímenes políticos de ambos países y de la historiografía convencional episódica.

Por último, conviene describir la naturaleza de este artículo. En efecto se trata de una periodización que intenta comparar y, cuando es necesario o posible, entrecruzar o conectar los procesos de formación del Estado en Nicaragua y Costa Rica. El periodo considerado es el que va desde la independencia de Centroamérica hasta el triunfo de la revolución sandinista en Nicaragua y el inicio del ocaso del estilo de desarrollo socialdemócrata o intervencionista adoptado por el Estado costarricense, a partir del fin de la guerra civil de 1948. La definición de las distintas etapas se ha hecho de acuerdo con las discontinuidades que se observan en Nicaragua, porque en este país el proceso de formación de Estado ha sido más accidentado que en Costa Rica. La preocupación central será identificar los procesos de centralización política, su éxito o su fracaso, y los procesos de adquisición de "atributos de estatidad", según la expresión de Oszlak, de ambos Estados.

Los Estados no solo penetran las sociedades, sino que también las "envuelven", las abrazan; de modo que fijan las poblaciones al territorio del cual reivindican su control. Si se toma en consideración lo planteado por Oszlak (42-63) al respecto, los retos o 
las tareas que afrontaron los Estados centroamericanos, del mismo modo que los otros Estados hispanoamericanos, tras su independencia, fueron los siguientes. Primero, centralizar el poder político, en especial, subordinar los llamados localismos y, como fundamento de lo anterior, monopolizar los medios de coerción. Segundo, delimitar el territorio bajo su control, es decir, definir sus fronteras en relación con sus vecinos y frente a poderes extrarregionales. Tercero, construir un "aparato" de Estado capaz de recaudar impuestos, sostener un ejército y proveer servicios a la economía y a la sociedad. Cuarto, darle un fundamento legítimo a su autoridad por medio de la creación de mecanismos de inserción y subordinación política del conjunto de la población. Quinto, hacerse reconocer como Estado viable y soberano en la comunidad internacional de Estados. Sexto, secularizar el poder, es decir, subordinar el poder eclesiástico al poder civil; y, por último, homogenizar a la población e inventar la nación mediante la creación de imágenes y prácticas de comunidad política.

En síntesis, los Estados centroamericanos, como los otros Estados latinoamericanos, tuvieron que resolver tres problemas básicos: centralizar el poder político, es decir, monopolizar los medios de coerción; darse un fundamento de legitimidad, mediante la invención de la nación; y proveer servicios al conjunto de la población. No obstante, los procesos de formación del Estado fueron contradictorios porque, por ejemplo, dependieron de expropiar a las municipalidades de sus atributos soberanos; sin embargo, requirieron que dichos organismos conservaran sus funciones administrativas propias y que fungieran también como relevo del poder central en formación. Lo anterior también es válido en lo que se refiere a la institución eclesiástica, la cual fue considerada necesaria para mantener la obediencia de la población y la cual, en las primeras fases de construcción estatal, mantuvo algunas de sus funciones como proveedora de servicios sociales a la población.

En Centroamérica, adicionalmente, la construcción del Estado en cada uno de los países que hoy existen tuvo que resolver dos asuntos particulares: desprenderse de la República Federal, tras su disolución en 1838; y hacerle frente al expansionismo de Gran Bretaña y Estados Unidos. Debe subrayarse que, para que las élites se atrevieran a emprender la tarea de construir un Estado e inventar una nación, fue indispensable que se convencieran de que su comunidad política era viable, es decir, sostenible internamente y capaz de ser tomada en serio y considerada un "Estado nación" por sus vecinos del Nuevo Mundo y por las potencias europeas, lo cual supuso abandonar o posponer indefinidamente el proyecto de reconstrucción de la unión centroamericana.

Así pues, el proceso de construcción de los Estados en Centroamérica puede ser visto como una continua tensión entre la búsqueda de un "centro común" y la conservación del poder local, tanto como poder real efectivo como poder administrativo. Por eso, los primeros conflictos políticos, tras la emancipación de España, giraron en torno al problema de a quién transferir la soberanía, ya fuese el Imperio mexicano, la federación o el Estado propio en particular. Este proceso no solo fue un asunto de 
negociación, sino también de conflicto, y está sintetizado en el problema de la centralización política, la cual fue primero una monopolización de los medios de coerción en algún ente político. Usualmente ese ente tenía asiento en una ciudad y era heredero de sus atributos soberanos. Tal proceso de centralización no fue ni automático ni exitoso en todos los casos.

Finalmente, conviene señalar que los actores políticos, hasta bien entrado el siglo XIX, carecían de una noción de formación de Estado; para ellos se trataba de establecer un régimen republicano basado en una Constitución. En este sentido, creían que lo que intentaban hacer era un asunto que pertenecía al mundo del derecho, el cual era perturbado por las pasiones humanas, llamadas con frecuencia pasiones de facciones o de partidos. Además, no separaban las nociones de Estado, nación y régimen político, de manera que se representaban confundidas. El elemento común de estas nociones era su carácter de entidades concebidas en el mundo del derecho y materializadas en un cuerpo jurídico de leyes y constituciones. ${ }^{10}$ Así, por ejemplo, no es un azar que tanto los protagonistas de los propios acontecimientos como casi todos los historiadores que a posteriori se ocuparon de ellos atribuyeran el fracaso de la República Federal Centroamericana a su Constitución, una mala copia, se ha repetido, de la Constitución estadounidense. ${ }^{11}$

\section{Etapas de formación del Estado en Nicaragua y Costa Rica}

\section{De la independencia a la guerra contra los filibusteros (1821-1857)}

La definición de esta etapa germinal de construcción de ambos Estados parece sencilla porque el contraste es muy evidente. En efecto, en Nicaragua este periodo es llamado la época de la "anarquía", 12 mientras que en la historiografía sobre Costa Rica se acepta que a inicios de la década de 1850 ya se había centralizado el poder político en la ciudad de San José y se había iniciado el proceso de invención de la nación costarricense, con sus conocidos atributos de excepcionalidad. Así pues, el desafío consiste en formular hipótesis plausibles sobre los resultados opuestos de los procesos de centralización política de ambos países.

Desde la óptica de esta investigación, el problema consiste en tratar de brindar razones para entender cómo, en el caso de Nicaragua, hasta el fin de la guerra contra los filibusteros, no hubo ninguna fuerza que lograra imponer la centralización política y militar y cómo, en el caso de Costa Rica, esa fuerza sí existió y logró imponer, finalmente a mediados de siglo, el monopolio de la violencia legítima en el conjunto del territorio que podía controlar.

Ahora bien, para comprender el proceso de formación de los Estados en Costa Rica y Nicaragua, se debe tener en cuenta que la independencia en Centroamérica no se obtuvo como resultado de una guerra, sino como efecto de la emancipación de 
México. En ese sentido, los marcos jurídicos e institucionales, el personal político y burocrático y las mismas élites existentes antes de la independencia fueron el fundamento sobre el cual se intentó construir el nuevo Estado federal y sus partes integrantes. De este modo, en esta parte del mundo la Constitución de Cádiz de 1812 y su restauración en 1820 fueron fundamentales, en términos de la evolución posterior de las comunidades políticas surgidas después de 1821 (Rodríguez, 1978).

La otra cuestión ya señalada, pero sobre la cual conviene insistir, es que tanto Centroamérica en su conjunto como las provincias, futuros Estados, tenían una conciencia álgida sobre su falta de viabilidad para constituirse como comunidad política soberana; de allí su deseo de encontrar un "centro común", término de la época, al cual integrarse. Por eso, no es un azar que los primeros intentos de construcción estatal en Centroamérica hayan asumido la forma de anexión al fugaz Imperio mexicano de Agustín de Iturbide (1821-1823) y el proyecto fallido de construcción de la República Federal Centroamericana (1824-1838). ${ }^{13}$

Como ya se adelantó, en esta primera fase llama la atención, cuando se compara Costa Rica con Nicaragua en términos de los procesos de centralización política, que en el primer caso se resolviera con relativa rapidez el asunto de la capitalidad, por medio del triunfo militar de San José sobre las otras ciudades del Valle Central; mientras que, en Nicaragua, tras la independencia se inauguró un largo periodo de disputas violentas entre sus élites y, en especial, entre Granada y León. Las dos vías opuestas tuvieron consecuencias distintas en los procesos de centralización política: por un lado, en Costa Rica cada conflicto militar se traducía en incremento de la autoridad del poder central, y, por otro lado, en Nicaragua se insertaba en un círculo vicioso de inestabilidad política crónica. De manera que desde los tiempos de la independencia se manifestó una oposición en los procesos de formación del Estado entre estos países: en Costa Rica, el proceso fue acumulativo; mientras que en Nicaragua fue más bien abortivo. ${ }^{14}$ También sus proyectos divergían ya que, aunque compartían el temor de ser dominados por Guatemala y reconocían la necesidad de un "centro común", para Costa Rica era prioridad conquistar su autonomía política, administrativa y eclesiástica en relación con León de Nicaragua, sede de la Diputación Provincial y del obispado, autoridades compartidas por ambos al momento de la independencia.

Se puede afirmar que el proceso de centralización política en Costa Rica adquirió un carácter irreversible en el periodo 1835-1837 y 1838-1842, durante los gobiernos de Braulio Carrillo (Obregón, 1991), es decir, cuando apenas se iniciaba el despegue de la economía del café, de manera tal que no se puede establecer una relación simple de causa y consecuencia entre la centralización política y el ascenso de la economía exportadora. ${ }^{15}$ En este sentido, fue en la esfera política y militar, en medio de una serie de conflictos con resultados irreversibles en 1823, 1835, 1842 y 1847, que el poder central asentado en San José terminó monopolizando el uso legítimo de la violencia. Así, se debe reconocer que el proceso de centralización política se había 
iniciado antes del despegue del café y que luego ambos corrieron paralelos a partir de la década de 1840, en particular, en la década siguiente.

De modo que, a inicios de la década de 1850, había en Costa Rica un Estado ya formado, cuyo poder se asentaba en una organización militar, basada en un cuerpo de milicianos encuadrados por un pequeño núcleo de veteranos y cuyas finanzas se fundaban en dos monopolios de origen colonial, el del aguardiente y el del tabaco. A la cabeza de este órgano político se encontraba un grupo de comerciantes y productores-exportadores de café, cuya figura máxima era el presidente Juan Rafael Mora. Así, se puede decir que en la década de 1850 confluyeron la centralización política, como un proceso ya irreversible producido en el marco de conflictos y negociaciones políticas entre las élites y de estas con las clases populares, y la consolidación de la economía agroexportadora del café. No obstante, se debe subrayar que no fue el café, valga la expresión, quien en forma automática produjo el Estado, sino los desenlaces de una serie de coyunturas en las cuales la concentración del poder del Estado en las élites de la ciudad de San José terminó siendo una realidad que ya no tuvo marcha atrás. ${ }^{16}$

Por el contrario, según la expresión de Knut Walter, Nicaragua fue un later starter, un caso tardío, en el proceso de formación del Estado y de la economía agroexportadora en el contexto centroamericano (Walter xvii). En efecto, las luchas continuas entre las élites, las cuales adquirieron la forma de conflicto entre Granada y León, a partir de la década de 1830, y la resistencia popular, la cual, en los años 1845-1849, asumió la forma de movimientos antifiscales, impidieron el proceso de centralización política en ese país. Además, los conflictos "externos", es decir, los de la Federación, los conflictos unionistas tras la disolución del pacto federal en 1838 y las disputas con los otros Estados centroamericanos tuvieron una fuerte repercusión en Nicaragua, mucho más que en Costa Rica, y exacerbaron los conflictos entre León y Granada. En fin, tampoco favoreció el proceso de centralización política la injerencia de Gran Bretaña y de Estados Unidos, ya que ambas potencias imperiales, a partir de 1840, empezaron a competir por la cuestión de la vía interoceánica.

En resumen, la dinámica interna, la dinámica política centroamericana y la geopolítica global en la región del Caribe y la América Central conspiraron contra la formación del Estado en Nicaragua durante este periodo. Este conjunto de vectores políticos locales, regionales e internacionales culminaron con la llegada, como invitado, del filibustero William Walker en junio de 1855 y con su control del gobierno del país desde octubre de ese año y hasta abril de 1857. Durante esta etapa, además, Nicaragua sufrió desmembramientos territoriales tanto frente a Costa Rica, en el Pacífico, con el llamado Partido de Nicoya, como frente a los británicos en el Caribe, con la Mosquitia, ambos fenómenos sintomáticos de la dificultad de este Estado para dotarse de los atributos básicos de "estatidad", según la expresión de Oszlak. 
No obstante, como lo recuerda Frances Kinloch, en el periodo llamado de la "anarquía” surgieron ensayos de centralización política que fracasaron, tanto en términos de monopolización de los medios de coerción, como de creación de un aparato fiscal. Por ejemplo, el intento de centralización política entre 1845 y 1849, llevado a cabo por medio del establecimiento de mayores impuestos, el monopolio del aguardiente y la creación de un ejército más profesional, generó la resistencia de las clases populares, bajo la forma de movimientos antifiscales y de las élites que controlaban las "ciudadesestado" de León y Granada (Kinloch 169-170). ${ }^{17}$ Conviene agregar que en distintas ocasiones se intentó establecer la capital en Managua, por ejemplo, durante el gobierno de Laureano Pineda en 1851.

Un nuevo ensayo de centralización y fortalecimiento del poder político, conducido por los conservadores, durante el gobierno de Fruto Chamorro (1853-1855), desembocó en una guerra civil, resultado de la oposición de las élites leonesas o liberales, la cual culminó con la intervención de William Walker. La medida pretendía acabar con la rivalidad entre León y Granada, territorios que se disputaban "la capital del Estado y el manejo de la cosa pública". El proyecto de Chamorro era claramente un programa de centralización política, similar al de Juan Rafael Mora en Costa Rica; sin embargo, la historiografía tradicional nicaragüense dominada por los conflictos interpartidarios no ha percibido este fenómeno y se ha limitado sea a condenar, sea a alabar la mano dura de Chamorro. ${ }^{18}$ De igual manera, Walker trató de fundar un Estado en Nicaragua mediante una política de "americanización", según argumenta Michel Gobat (Gobat, 2018).

Así las cosas, la llegada de los filibusteros como consecuencia de un intento abortado de centralización política en Nicaragua y el papel desempeñado por Costa Rica en su derrota tienen un valor sintomático sobre el nivel alcanzado por ambos países en su proceso de formación del Estado. Un asunto que no hay que perder de vista es que la formación de los Estados en América Central fue un proceso interdependiente, en el cual intervinieron la emulación, la imitación y las rivalidades, de modo que podría decirse, por ejemplo, que el Estado en El Salvador se construyó en el siglo XIX mediante un proceso continuo y contradictorio de emancipación de la tutela del Estado de Guatemala. De manera similar, el Estado en Costa Rica se construyó en el marco de una relación conflictiva por cuestiones territoriales con Nicaragua.

Dicho fenómeno fue bastante claro en los años previos a la llegada de Walker, ya que, dada la debilidad del poder central en Nicaragua, Costa Rica, sobre todo en la época de Mora, tuvo claros apetitos en relación con el río San Juan y la margen sur del lago de Nicaragua. En este punto confluían los conflictos entre los Estados centroamericanos con fenómenos geopolíticos globales, en un proceso de entrecruces de los procesos de formación de Estado en Estados Unidos, México y América Central. ${ }^{19}$

El éxito de la centralización política alcanzada por Costa Rica a mediados del siglo XIX estaba en relación con la naturaleza de sus élites. En efecto, las formas de 
interacción política y económica de las élites costarricenses de esos años, en donde negocios, parentescos y política se entremezclaban y en donde los conflictos se manejaban a partir del principio de un uso restringido y delimitado de la fuerza y de la violencia, darían cuenta del éxito de este primer momento del proceso de formación del Estado. En la década de 1850, estas élites ya compartían un proyecto político, la construcción del Estado, y un proyecto económico, la producción y exportación de café. De este modo, el carácter relativamente ordenado de la vida política costarricense del siglo XIX estaba en relación tanto con el éxito de la centralización política como con la forma en que las élites enfrentaron sus conflictos, en el plano del poder y en el de los negocios. Tampoco se puede idealizar lo que era este poder central, porque su autonomía frente a los grupos dominantes era bastante limitada, ya que estos tenían una perspectiva patrimonialista y, en la práctica, consideraban al Estado no como una cosa pública. Esta realidad se manifestó dramáticamente con el fusilamiento de Juan Rafael Mora en 1860.

Para entender las razones de la centralización política de Costa Rica a mediados del siglo XIX se deben recordar las relaciones de estas élites con los militares, quienes eran meros agentes subordinados de sus distintas facciones y no actores por derecho propio, circunstancia que permitiría comprender uno de los aspectos claves del sistema político costarricense, el reducido peso histórico del militarismo. En fin, las características de la centralización política de Costa Rica fueron similares a las de Guatemala, es decir, el monopolio de los medios de coerción, pero en Costa Rica el Estado pasó a ser el "centro común" de individuos o grupos sociales, económicamente definidos, y no de corporaciones como las comunidades indígenas, a la manera de Guatemala. ${ }^{20}$

Además, aunque la financiación de la centralización política se hizo en detrimento de las clases populares, ya que el aguardiente y el tabaco, artículos de amplio consumo popular, eran monopolios estatales, el naciente Estado y las élites no lograron impedir que dichas clases pudiesen tener acceso a una frontera agrícola abierta y disfrutar de salarios ventajosos, como consecuencia de una escasez de mano de obra, al menos hasta fines del siglo XIX. En fin, estos grupos participaron con su propia agenda en el proceso político como lo muestra, por ejemplo, su papel en la caída y el fusilamiento de Juan Rafael Mora (Acuña y Molina, 1991). Por tanto, el Estado costarricense era más un organismo de "ciudadanos", acorde con la forma moderna de soberanía, que de "pueblos", a la manera de las soberanías de antiguo régimen, según la caracterización de Guerra (1993).

En consecuencia, la divergencia inicial entre ambas comunidades políticas se puede intentar explicar en términos de sus características institucionales, el carácter de sus élites y de determinados condicionamientos estructurales. Así, es posible que la divergencia haya sido consecuencia de que, antes de 1821, en Nicaragua había más burocracia e instituciones que en Costa Rica; de modo que las élites del antiguo régimen 
tenían más consistencia y más intereses que defender que las élites de Costa Rica. Aquí, la burocracia colonial era ínfima y estaba subordinada en términos político-administrativos a las autoridades respectivas de León. Como señala Xiomara Avendaño, en una perspectiva de historia institucional, los Estados o estamentos en posesión de derechos y privilegios impidieron la centralización del poder político en Nicaragua hasta mediados del siglo XIX. ${ }^{21}$

Debe señalarse, además, que tanto para Nicaragua como para Costa Rica el proceso constitucional gaditano fue importante en la medida en que permitió que se establecieran municipalidades en todas las ciudades, lo cual facilitó articular en un plano institucional los intereses locales o localistas. Además, dicho proceso vinculó formalmente a ambas provincias en una sola unidad de gobierno y administración, la citada Diputación Provincial. Otro factor que puede haber sido determinante es que, para el momento de la independencia, en términos económicos, las élites de San José ya habían sobrepasado a las de otras ciudades del Valle Central, es decir, Cartago, capital colonial, y las nuevas ciudades aparecidas en el siglo XVIII, Heredia y Alajuela. Posiblemente las élites de Costa Rica, por ser más pequeñas y por ser el resultado de un proceso de expansión económica y demográfica en el siglo XVIII, cuyo origen estuvo en Cartago, estaban relacionadas por estrechos vínculos de parentesco y negocios y, de este modo, eran más homogéneas. En fin, la condición social y económica de los productores rurales en Costa Rica, campesinos y jornaleros mestizos, la de ser libres en el sentido de no estar sometidos a coacciones de tipo extraeconómico, fue determinante en las relaciones que establecieron con quienes alcanzaron el control efectivo del poder del Estado.

Por oposición, en Nicaragua las élites de León y Granada estaban en una situación de equilibrio de fuerzas, en la cual no era evidente que una pudiese imponerse sobre la otra. En la base de las correlaciones de fuerzas entre las élites, se debe señalar un condicionamiento estructural en el sentido de que en Nicaragua, Granada y León funcionaban como dos economías separadas y en competencia, de modo que cada una de estas ciudades presidían mundos con muy poca integración entre sí; mientras que en Costa Rica, el Valle Central se había constituido en un espacio económico ya integrado, cuyo polo dominante era la ciudad de San José. ${ }^{22}$

La explicación de Burns, tomada de Humberto Belli, es que las dos ciudades, León y Granada, eran mundos económicos autárquicos, cada uno con su conexión autónoma respecto de los mercados externos. Para Burns, la llamada "anarquía" se explica por el conflicto entre ambas ciudades, pero también por el equilibrio de fuerzas entre las élites, que llama los patriarcas, y las clases subalternas o subordinadas que denomina, el pueblo. De este modo, la centralización política no se logró por una especie de empate en términos de correlación de fuerzas en el seno de las élites y de estas con las clases populares. A estas cuestiones de clase se sumaban las divisiones y tensiones étnicas, tanto con las comunidades indígenas, como con mulatos y pardos, como ha sido señalado por Justin Wolfe. ${ }^{23}$ 
Un asunto muy interesante de la interpretación de Burns sobre el periodo de la "anarquía" es que sostiene que las élites de Nicaragua tenían una visión similar de su futuro económico, como país inserto en la economía mundial y beneficiado por la posibilidad de una ruta canalera. Su "destino manifiesto", según la expresión de Kinloch, era la construcción del canal, lo cual haría de su país un emporio. No obstante, a pesar de más o menos querer lo mismo en términos de su desarrollo futuro, estas élites no lograron la centralización política, sino hasta después de 1857. Dicha circunstancia ilustra muy bien la hipótesis de este artículo, en tanto que los procesos de formación de Estado no se derivan automáticamente de realidades económicas, sino que se articulan en la dimensión política del proyecto, es decir, que solo cuando en determinada coyuntura surge una fuerza política y militar capaz de prevalecer sobre todas las demás se desencadena la centralización política.

Burns lo dice de una manera muy apropiada: las élites de Nicaragua querían ser modernas, pero no sabían cómo gobernarse. En última instancia, su explicación del fenómeno es política; sostiene que, en Nicaragua, a diferencia de Guatemala con Carrera y Costa Rica con Carrillo, no surgió un caudillo capaz de imponer la centralización política (Bradford Burns 106-107). En términos más generales, Antonio Esgueva considera que la historia de Nicaragua presenta unas constantes históricas, "una historia muy repetitiva", de fragilidad institucional, de predominio del Poder Ejecutivo, de continuismo, de militarismo y de elecciones que son más apariencia que realidad, como bien se expresa en una cínica frase del presidente del Consejo Supremo Electoral de tiempos del primer Somoza, en 1947: “Voten, voten que luego cuento yo" (Esgueva 15). ${ }^{24}$

En suma, hasta la llegada de los filibusteros, las élites nicaragüenses protagonizaron un empate político militar que conspiró contra la formación del Estado. A partir de este reconocimiento de lo político, como la esfera en donde se deben buscar las explicaciones para ver estos resultados divergentes de dos procesos de centralización política, se puede proponer la hipótesis de que esta depende en definitiva de una lectura política que hacen las élites de sus intereses económicos y de una valoración de las correlaciones de fuerza existentes en su seno y entre ellas y las clases subalternas. Tanto las élites costarricenses como las nicaragüenses querían el llamado progreso y sabían que este dependía de alcanzar el orden político; sin embargo, en esta etapa, las costarricenses sí pudieron actuar en consecuencia, mientras las nicaragüenses tuvieron que padecer el trauma de la intervención filibustera para alcanzar un primer acuerdo al respecto. 


\section{Del final de la guerra contra los filibusteros al inicio de la intervención de Estados Unidos (1857-1912)}

En Costa Rica, el final de la guerra contra William Walker, en la cual el país había jugado un papel determinante de la mano del presidente Juan Rafael Mora, fue seguido por un periodo de turbulencias políticas, manifestado con la caída de Mora, en 1859, tras diez años de estar en el poder, y su fusilamiento, en 1860. No obstante, estos hechos graves de alteración del orden político no produjeron un retroceso de la centralización política que venía ya de al menos dos décadas atrás, ya que las élites de este país, a pesar de sufrir algunas arbitrariedades durante el gobierno de Mora, estaban de acuerdo con tener un Estado que estuviese a su servicio. Además, en este periodo el Estado costarricense se fue acoplando al modelo agroexportador, en la medida en que sus ingresos pasaron a depender cada vez más de los impuestos al comercio exterior, es decir, a las importaciones esencialmente, y, a partir de 1870, con el ascenso de los liberales, hizo de la construcción de un ferrocarril al Caribe su magno proyecto. Este fue el momento en el cual el Estado costarricense adquirió los ribetes de Estado oligárquico, según lo concibe Torres-Rivas, al servicio del proyecto agroexportador (Torres-Rivas, 1973). En fin, a partir de finales de la década de 1880, el Estado costarricense parecía decidirse por darle un fundamento más sólido a su legitimidad, mediante un primer esfuerzo de puesta en marcha de un proceso de expansión de la educación primaria y por medio de la difusión y la propaganda de una identidad nacional, fundada en la idea de Costa Rica como país excepcional. Como ya se adelantó, esa invención nacional había ocurrido previamente y se presentaba ya acabada en la década de $1850 .^{25}$

Existe un amplio acuerdo entre los especialistas en el sentido de reconocer que fue solamente tras el fin de la guerra contra los filibusteros que ocurrió el primer proceso de centralización política en Nicaragua, es decir, cuando se inició la formación del Estado. ${ }^{26}$ Así, como consecuencia de la traumática intervención de los filibusteros, su usurpación del poder y la guerra de resistencia que desencadenó, las élites nicaragüenses decidieron aceptar, no sin reticencias, un proceso de centralización política. De este modo, tras la derrota de Walker, inició la época de los llamados Treinta Años (1857-1893), dominada por los conservadores de Granada, quienes pusieron en marcha un proyecto de state making, el cual encapsuló, pero no eliminó totalmente, el llamado "localismo", tanto en León como en Granada. Lo anterior a pesar de que esta época fue testigo del ascenso de Managua como capital y como nuevo polo económico, gracias al desarrollo de la economía de exportación de café.

José Luis Velázquez señala que la Constitución de 1859 sancionó en algunos de sus artículos la división de las élites nicaragüenses entre sus componentes principales asentados en León y Granada; de modo tal que, por ejemplo, el poder judicial fue dividido en dos partes, una con asiento en León y otra en Granada. También el poder 
local conservó sus prerrogativas mediante la institución de los prefectos. En León y en Granada se crearon prefecturas y, en las ciudades que eran sus satélites, subprefecturas. Jurídicamente, las prefecturas eran instituciones intermedias entre el poder ejecutivo y los consejos municipales; pero en la práctica acumulaban una serie de funciones políticas, militares, administrativas, fiscales y de policía que las convertían en verdaderos centros de poder local. Esta misma partición entre ambas ciudades afectaba al ejército, de modo que, según Velázquez, no tenía un carácter nacional, sino local. Este autor agrega que, en opinión de Paul Levy, quien estuvo en Nicaragua en esos años, el prefecto era "virtualmente un pequeño presidente de su departamento" (Velázquez, 1992). ${ }^{27}$ Además, en esa época, el Estado no llegó a estar, en forma total y efectiva, por encima de personas y grupos y después de 1889, en el ocaso de la República conservadora, reapareció la política basada en el discurso binario leoneses frente a granadinos.

La función de este "Estado mínimo", según la expresión de Arturo Cruz, ${ }^{28}$ era ofrecer las condiciones institucionales para la acumulación de capital, en particular la expansión cafetalera y para asegurar un mínimo de soberanía externa frente a los poderes imperiales en el área y frente a los otros Estados del istmo, interesados todos en el valor geoestratégico de Nicaragua. Así, la centralización política, conducida por los conservadores durante el periodo de los Treinta Años, formó un organismo que adquirió las características de Estado oligárquico, en la medida en que estuvo al servicio de los intereses de la agroexportación y ejecutó un programa similar al que en otros países centroamericanos realizaron los liberales, a partir de la década de 1870.

Así las cosas, los conservadores nicaragüenses actuaron en los hechos como liberales, lo cual tiene consecuencias importantes para el análisis. Además, para todos los efectos prácticos este "Estado mínimo" era soberano solo en una porción del territorio de Nicaragua, es decir, la franja del Pacífico y sus extensiones hacia la ribera oriental del lago de Nicaragua y el norte del país. En este periodo la hacienda pública nicaragüense era similar a la de los otros países centroamericanos, ya que en sus ingresos hubo un predominio inicial de los estancos del aguardiente y del tabaco y, a partir de 1875, los impuestos a las importaciones pasaron a ocupar el primer lugar. En cuanto a los egresos, el principal rubro era el pago de la deuda y el siguiente los gastos en las fuerzas armadas. No obstante, Arturo Cruz admite que el ejército era débil.

El Estado creado por los conservadores dejó, por tanto, una centralización política incompleta y, además, poco se ocupó de los problemas de su legitimación, es decir, poco avanzó en el proceso de invención de la nación. Según lo que plantea Burns, en la era de los conservadores el Estado se formó, pero sin buscar legitimarse ante las clases populares; se creó una "nación de élites", pero sin pueblo. De modo que la formación del Estado no se acompañó de un proceso efectivo de invención nacional y de integración de la población a la política o de creación de un régimen de ciudadanía. Por su parte, Arturo Cruz insiste en que la legitimación del Estado quedó inacabada porque no se dio espacio a los sectores medios y porque no se buscaron 
mecanismos de integración de las clases populares. En suma, con los conservadores por fin se formó un Estado en Nicaragua, pero sus atributos de "estatidad" aún no alcanzaron suficiente plenitud como para que el proceso de centralización política no fuese reversible, como se evidenció en el periodo siguiente.

Precisamente, el régimen de José Santos Zelaya (1893-1909) es considerado como el que vendría a profundizar el proceso de centralización política en Nicaragua y a intentar darle plenitud a los atributos de "estatidad" del Estado. En particular, Zelaya sometió a la Iglesia y al poder municipal; la última rebelión con una base local contra el poder central asentado en Managua tuvo lugar en León. A partir de este momento ya ninguna municipalidad volvió a disputar el poder al gobierno central.

Ahora bien, la centralización del poder político se realizó mediante la instauración de un régimen dictatorial. En su voluntad de monopolizar los medidos de coerción, Zelaya buscó la profesionalización del ejército y el presupuesto militar se incrementó sobre todo en los últimos años de su régimen, hasta lograr ser el principal rubro de gasto del fisco. Es muy sintomático del proceso de construcción de Estado la "reincorporación" de la Mosquitia, es decir, la implantación soberana, más formal que efectiva como la historia posterior lo mostró, del Estado nicaragüense en esa parte del territorio que había estado bajo control de las poblaciones locales en alianza o bajo el tutelaje de los británicos. No hay que olvidar que mediante el régimen concesionario la "reincorporación" de la Mosquitia fue acompañada de un ascenso de los enclaves mineros, madereros y bananeros en esta región.

Como era de esperarse, este proceso de centralización política se puso al servicio del crecimiento agroexportador, mediante la ampliación de la red ferroviaria y de caminos. En este sentido, Zelaya convirtió al Estado en un protagonista clave del crecimiento económico del país. El intento de Zelaya de profundizar los atributos de "estatidad" del Estado nicaragüense y sus pretensiones de jugar un papel protagónico en la geopolítica centroamericana desataron la oposición armada de las élites de su país, tanto de los conservadores como de facciones liberales, además de nuevas formas de resistencia popular y el rechazo de Estados Unidos que había iniciado el establecimiento de su sistema de Estados-clientes en el contexto del comienzo de las obras del canal de Panamá. ${ }^{29}$ Tales circunstancias y el carácter unipersonal del régimen desembocaron en una insurrección en la Mosquitia y en la intervención militar de Estados Unidos..$^{30}$

En ese momento, se cerró el periodo de construcción estatal en Nicaragua, el cual inició tras la derrota de Walker en 1857, y se abrió una nueva etapa en la cual este país se convirtió en un protectorado de Estados Unidos, despojado del atributo básico de "estatidad", la soberanía, y sometido de nuevo a un funcionamiento como "Estado mínimo", pero aún más "mínimo" de lo que había sido el de la época de los Treinta Años. De este modo, se puso de manifiesto que el proceso de construcción del Estado en Nicaragua no era irreversible. En esta etapa sorprende la reaparición de las luchas 
de facciones y la consecuente puesta en entredicho del monopolio de los medios de coerción en manos del Estado; en cierto sentido, parece una vuelta a la fase anterior a 1857, con la diferencia de que sí existe propiamente un aparato de Estado.

En comparación con Costa Rica, este Estado brindó servicios ínfimos al conjunto de la población, tuvo poca legitimidad y su régimen político padeció un déficit de ciudadanía, en la medida en que avanzó muy poco en las tareas de invención de la nación, circunscrita a sectores urbanos del Pacífico nicaragüense. En fin, fue en el gobierno de Zelaya, con la construcción definitiva del canal en Panamá, que terminó el gran sueño de las élites nicaragüenses desde los tiempos de la independencia: el canal de Nicaragua. Si en 1893, al final del periodo de los conservadores, se podía afirmar que el Estado en Nicaragua había logrado notables avances en el proceso de adquisición de atributos de "estatidad", al final del periodo liberal ese proceso había retrocedido. En la agenda volvía al primer plano el asunto de la centralización política, mediatizada por el problema de la intervención militar, política y económica estadounidense. La caída de Zelaya es también una muestra de las interconexiones de los procesos de formación de los Estados en el espacio centroamericano y de estos con el ascenso imperial de Estados Unidos.

En suma, a comienzos del siglo XX, como había ocurrido tras la independencia, se puede observar una evolución divergente del Estado costarricense, frente al Estado nicaragüense. En efecto, a inicios de la Primera Guerra Mundial es claro que Costa Rica protagonizó ha protagonizado un proceso acumulativo de construcción estatal, proceso que ha sido profundizado con la llegada de los liberales al poder en 1870. El despliegue del Estado costarricense en este periodo es contradictorio, ya que, si bien ha ampliado sus funciones, tanto económicas como sociales, con la expansión de la educación primaria, al mismo tiempo ha perdido autoridad y soberanía en una porción importante de su territorio. En efecto, en la región del Caribe se consolidó, a partir de 1890, la producción de banano en una modalidad de enclave. Además, en esos años el Estado costarricense, al igual que otros en el istmo, aceptó que había quedado inserto en el sistema de Estados-clientes, recién establecido por Estados Unidos en el Caribe y América Central.

En todo caso, lo nuevo se refiere a la legitimación del poder del Estado en la medida en que en Costa Rica en esta etapa se observa la aparición de una clase política civil, el llamado "Olimpo", es decir, un grupo de personas que no eran miembros de la oligarquía cafetalera y que asumieron la administración del Estado; en esos años también, como ya se indicó, despegó el proceso integrar social y culturalmente a la población mediante la extensión de la educación primaria. ${ }^{31}$ Además, las elecciones adquieren connotaciones más reales y la competencia en las urnas, aunque amañada y manipulada, pasó a ser la forma principal por medio de la cual los gobiernos se escogían (Lehoucq y Molina, 2002). 
Por último, en Costa Rica parece ser más exitoso el proceso de invención de lo nacional y su difusión entre los habitantes. Así, se puede afirmar que en las primeras décadas del siglo XX la mayoría de la población, la cual habitaba en el Valle Central, ya ha empezado a creer en el kit ideológico y cultural del excepcionalismo "tico". A inicios del siglo XX, empieza a decirse de Costa Rica que es una democracia, en donde el pueblo elige a sus gobernantes. En suma, hacia la Primera Guerra Mundial los atributos de "estatidad" del Estado costarricense parecen haber alcanzado su madurez. Ya no parece estar en el tapete la cuestión de la centralización política, la cual se da por descontada, y la agenda se traslada al problema del régimen político y al papel que el Estado debe cumplir en la vida social y económica. En este sentido, empiezan a hacerse oír voces que critican el carácter liberal del Estado y que señalan los límites de la pretendida democracia costarricense. El problema ya no es el Estado, sino las funciones que debe cumplir en el proceso económico y en las relaciones entre grupos sociales y el carácter del régimen político en el cual se va a sustentar.

\section{El declive del liberalismo, el Estado "reglamentista" en Costa Rica y el Estado intervenido por Estados Unidos en Nicaragua (1914-1936)}

Puede ser útil definir esta etapa para ambos países, aunque el fenómeno más relevante en términos del proceso de formación del Estado sea el estatuto de protectorado estadounidense de Nicaragua, porque los orígenes del Estado moderno se remontan a este periodo en ambos países, incluso en la Nicaragua intervenida. A partir de 1940, inicia el desarrollo del Estado de bienestar en Costa Rica y fue a partir del ascenso de Somoza al poder, en 1936, que el Estado nicaragüense ingresó en una nueva fase de adquisición de atributos de "estatidad".

A partir de la Primera Guerra Mundial empezaron a hacerse evidentes los problemas del Estado liberal y del modelo agroexportador en Costa Rica. Es representativo al respecto el abortado gobierno del presidente Alfredo González Flores (1914-1917), quien intentó poner en marcha un conjunto de reformas para otorgar un mayor protagonismo al Estado, sobre todo en la esfera de la economía, y darle un nuevo fundamento fiscal mediante impuestos directos. También dicho gobierno fundó el primer banco estatal, el cual, a partir de 1936, asumió funciones de banca central y desarrolló una política de crédito para los pequeños y medianos productores rurales. En esta misma época surgió en Costa Rica lo que se denominó la "cuestión social", es decir, el tema de los derechos de los trabajadores y las primeras demandas de legislación social, planteadas por una constelación de sectores "obreros" y clases medias en formación.

En tal contexto, el Estado costarricense comenzó a desarrollar sus primeras políticas de intervención de la economía agroexportadora y sus primeras políticas sociales. ${ }^{32}$ De esta manera, el Estado empezó a insinuarse como regulador de las interacciones entre clases sociales y de las relaciones entre los agentes económicos de la 
actividad cafetalera. En la década de 1930, en el contexto de la depresión, algunas de estas fuerzas y demandas sociales pasaron a ser articuladas en el plano político por el Partido Comunista de Costa Rica. Es interesante señalar que en estos años el Estado costarricense creó dos empresas públicas, el Ferrocarril al Pacífico, terminado en 1909, y el Banco de Seguros fundado en 1924. De igual modo, el Estado adquirió mayor visibilidad y protagonismo tanto en la educación como también en asuntos de salud pública. ${ }^{33}$ Fue en la década de 1920 cuando el mito de "más maestros que soldados" se acercó a la realidad, ya que tomados por separado los gastos en seguridad pública y en gobernación fueron inferiores a los gastos en educación pública y, adicionalmente, los gastos militares se fueron reduciendo.

Sin embargo, en la década de 1920, el Estado costarricense invertía la mayor parte de sus recursos en obras públicas y en el pago del servicio de la deuda. A partir de 1895 y hasta 1914, los gastos en educación no bajaron del 10 por ciento del gasto total y oscilaron entre el 10 y el 16 por ciento. Cabe agregar que, partir de 1903, el Estado costarricense casi gastó lo mismo en guerra y marina, es decir, seguridad pública, que en educación, alrededor de un 15 por ciento. No obstante, el gasto en educación fue siempre inferior a lo gastado en fuerzas armadas y policía en conjunto (Román, 1995)..$^{34}$ Desde una perspectiva más bien tecnocrática, este comportamiento del Estado costarricense será criticado por Rodrigo Facio y los jóvenes socialdemócratas en los años 1940, por considerarlo "reglamentista", es decir, casuístico en sus intervenciones y carente de un plan coherente y "científico". ${ }^{35}$ De todos modos, después de 1914, se multiplicaron los signos de que el Estado liberal costarricense se aproximaba a su ocaso.

En relación con la situación de Nicaragua durante la fase de la ocupación de Estados Unidos, Michel Gobat señala que la política del gobierno estadounidense "congeló" el proceso de construcción del Estado y perjudicó a sectores de la elite, en particular a los granadinos. ${ }^{49}$ Knut Walter también reconoce en que en ese periodo el Estado nicaragüense perdió atributos soberanos básicos porque fue intervenido fiscal, financiera, militar y políticamente. Así, las autoridades estadounidenses estacionaron tropas en el país, aunque se trató de un contingente pequeño, controlaron las aduanas y determinaron el funcionamiento de las finanzas públicas. Por imposición de las autoridades de ocupación, más del 40 por ciento del gasto estatal se dedicó principalmente al pago del servicio de la deuda y no se hizo inversión alguna en infraestructura (Walter, 2000). Así, en esta etapa se regresó a una especie de "Estado mínimo", el cual, además, carecía de uno de sus atributos esenciales, la soberanía. Este Estado intervenido curiosamente no fue capaz de poner fin a las luchas de facciones armadas y el caudillo conservador Emiliano Chamorro, continua y exitosamente, puso en entredicho el monopolio estatal de los medios de coerción hasta la fundación de la Guardia Nacional, en 1928.

Dentro de esta misma lógica, la llamada "cuestión social" asumió el carácter de una lucha armada nacional y popular, dirigida por Augusto C. Sandino. Esta etapa 
recuerda el periodo posterior a la independencia, porque volvieron a predominar las disputas y los conflictos militares entre liberales y conservadores, junto con levantamientos populares. Una vez más, se puso de manifiesto que uno de los rasgos básicos del proceso de construcción del Estado en Nicaragua era su reversibilidad, es decir, su carácter no acumulativo en donde lo andado en términos de centralización política y de institucionalización del poder en una determinada etapa era deshecho en algún momento posterior. Pareciera que las élites nicaragüenses no valoran o no tienen conciencia de que tener un Estado como algo compartido puede ser útil y conveniente a sus intereses y funcional para el ejercicio de su dominación. No obstante, como señala oportunamente Knut Walter, el Estado de la ocupación dejó como legado un conjunto institucional sobre el cual se edificó el Estado somocista.

En efecto, Estados Unidos estableció un protectorado en el cual se pretendió, paradójicamente, crear un Estado fuerte, con el fin de asegurar los intereses geopolíticos de la potencia en el istmo. Así, durante el protectorado se creó la Recaudación General de Aduanas (RGA), en 1911, responsable del cobro de los derechos aduaneros, cuyo principal destino era el pago de la deuda externa e interna de Nicaragua. La RGA fue administrada por un estadounidense hasta la década de 1950. En 1912, se fundó el Banco Nacional de Nicaragua y, en 1917, se estableció la Alta Comisión, con una directiva en su mayoría compuesta por estadounidenses, encargada del control y supervisión del presupuesto nacional. En 1923, se promulgó la Ley Dodds, con la cual se estableció una legislación electoral moderna para Nicaragua, vigente en la práctica hasta 1979. En fin, mediante el tratado Cuadra Pasos-Munro, surgió la Guardia Nacional. Según Walter: "Este sería un Estado hipotecado e intervenido, pero, no obstante, un Estado. Por otra parte, las instituciones creadas en el protectorado serían las mismas sobre las cuales se montó posteriormente el régimen somocista" (Walter 332).

Héctor Pérez Brignoli ofrece cifras que permiten, en general, comparar el nivel de desarrollo del Estado en los países centroamericanos a mediados de la década de 1920 y, en especial, contrastar Nicaragua con Costa Rica (Pérez Brignoli 114). El autor parte de la siguiente constatación: más del 50 por ciento de los ingresos de los Estados centroamericanos procedían de los derechos aduaneros y, como las élites invertían muy poco, el gasto público era la principal fuente de inversión para el desarrollo futuro. Ahora bien, a fines de los años 1920, los patrones de gasto público de Costa Rica, ya señalados, se tradujeron en un PIB per cápita mayor al de los otros países del istmo, el cual apenas representaba una cifra de entre el 80 y 60 por ciento del PIB de Costa Rica. Dicho país también mostraba cifras superiores en comercio exterior y gasto público y en indicadores económico-sociales, como tasa de alfabetización, tasa de crecimiento de la población y esperanza de vida. Así, la diferencia de Costa Rica, en relación con los otros países centroamericanos, era consecuencia de la naturaleza y las políticas de su Estado. 
Las cifras que el autor presenta, relevantes para este análisis son las siguientes:

Tabla 1

NIVEL DE DESARROLLO DE COSTA RICA Y NICARAGUA DURANTE LA DÉCADA DE 1920

\begin{tabular}{lcc}
\hline & Costa Rica & Nicaragua \\
\hline Tasa de analfabetismo & $24 \%$ & $72 \%$ \\
Tasa de crecimiento de la población & $2.3 \%$ & $1.1 \%$ \\
PIB per cápita & 308 USD $^{*}$ & 172 USD $^{*}$ \\
Sector público (\% del PIB) & $3.0 \%$ & $1.0 \%$ \\
Exportaciones per cápita & 136.0 & 43.0 \\
Importaciones per cápita & 79.0 & 36.0 \\
Km de ferrocarril por cada 1000 habitantes & 1.49 & 0.36 \\
Gasto público en educación (per cápita) & 1.6 & 0.5 \\
Gasto público en desarrollo (per cápita) & 14.3 & 6.2 \\
\hline
\end{tabular}

Fuente: Elaboración propia a partir de Pérez Brignoli 114. *Dólares de 1970. **Dólares corrientes.

Estos datos permiten concluir que el Estado en Costa Rica tenía una mayor presencia y protagonismo y que, además, cumplía más funciones de legitimación que el de Nicaragua. En síntesis, durante la ocupación, Nicaragua no era un Estado nacional, sino una dependencia administrada con instituciones públicas por un Estado imperial, instituciones cuyos objetivos no eran los de la nación o más precisamente de sus élites dominantes, sino los de la potencia ocupante. Desde esta óptica, la diferencia entre el proceso de construcción estatal en Costa Rica y en Nicaragua radica, como se ha mencionado, en que en este país el Estado nunca terminó de nacionalizarse, es decir, proponerse ser representativo del conjunto de sus habitantes.

\section{De la fundación del Estado somocista y del Estado intervencionista en Costa Rica a la Revolución sandinista y al ascenso del neoliberalismo en Costa Rica (1936-1979)}

La construcción del Estado somocista tuvo por núcleo y fundamento la monopolización de los medios de coerción en manos de la Guardia Nacional, la cual ocurrió primero mediante el desarme de las bandas de caudillos liberales y conservadores y, posteriormente, por medio del asesinato deSandinoy el aniquilamiento 
de sus fuerzas. Así, Somoza y su Estado se impusieron porque triunfaron en el plano militar y monopolizaron en forma duradera los medios de coerción. ${ }^{36}$ En este aspecto, hubo consenso entre conservadores y liberales, en el sentido de que debía imponerse el orden; por esta razón, ambas facciones justificaron el asesinato de Sandino.

El somocismo fue también un proyecto de construcción nacional en la medida en que pretendía, al menos en el papel, integrar a los sectores populares y a las clases medias al régimen político, mediante políticas estatales que los favoreciesen. En ese sentido, la búsqueda de legitimidad implicaba un Estado más activo y más involucrado en la vida social y económica, para disgusto de los conservadores. Somoza pretendía ser un político de nuevo tipo, un árbitro entre facciones y la encarnación de la nación. No obstante, Somoza inscribió este proyecto de construcción estatal e invención nacional en la vieja política clientelista, expresada en sus relaciones con los seguidores del partido liberal, con el movimiento obrero y artesanal y por medio del reparto de las instancias gubernamentales como botín político (Gould, 1997). Una manifestación clara de la voluntad de Somoza de centralizar el poder fue el sometimiento y subordinación de las municipalidades a partir de 1937. El gobierno convirtió a los gobiernos locales en instrumento del poder central y más concretamente de la presidencia de la República.

A pesar de la crisis de 1930, es signo del proceso de construcción de Estado el hecho de que, en los primeros años del gobierno de Somoza, entre 1936 y 1945, los ingresos fiscales se duplicaron. Además, en este periodo se inició un protagonismo económico estatal, nunca antes visto en la historia de Nicaragua, manifestado por el fenómeno del peso de la banca estatal en el sistema financiero, la cual otorgaba hasta el 80 por ciento de los créditos. También durante la primera década del gobierno de Somoza se incrementó el personal del aparato represivo y de la burocracia. Como en los otros países y como en la fase anterior de la historia de Nicaragua, los principales ingresos fiscales eran los derechos aduaneros que representaban hasta alrededor del 50 por ciento de las rentas estatales. Resulta interesante notar que después de estos el segundo rubro de los ingresos del fisco eran las empresas públicas como el ferrocarril. Tras estos se encontraban las rentas del aguardiente y la del tabaco. Ahora bien, el gasto estatal se concentraba en el pago del servicio de la deuda, las fuerzas armadas, la policía, y las obras públicas. En todo caso, es claro que a pesar de las promesas de Somoza los gastos sociales, tal y como los caracteriza Walter, salud, educación, trabajo y agricultura, no eran su prioridad, ya que solo en forma excepcional superaron en conjunto el 10 por ciento del gasto total. La prioridad de la política fiscal era la promoción de la agroexportación, mediante el desarrollo de la infraestructura, el mantenimiento del orden público y el cumplimiento con las obligaciones de la deuda externa.

En la década siguiente, 1945-1956, la composición de los ingresos del Estado cambió, ya que las rentas aduaneras se incrementaron hasta alcanzar alrededor de un 60 por ciento; mientras que los otros ingresos declinaron, especialmente los procedentes de 
las empresas públicas. Estos declives fueron compensados por un aumento al final del periodo de los ingresos procedentes de impuestos directos. En todo caso, es claro el vínculo estrecho entre prosperidad agroexportadora y crecimiento de los ingresos fiscales, basados en un sistema totalmente regresivo. En el caso de Nicaragua, a los buenos precios del café vino a sumarse el boom de las exportaciones de algodón (Williams, 1986). ${ }^{37}$

En relación con el gasto, el cambio más notable fue el incremento del rubro de policía y fuerzas armadas hasta aproximadamente un tercio del total, mientras que el porcentaje en educación se duplicó hasta alcanzar un 10 por ciento del total. En fin, en términos del desarrollo del poder del régimen, es importante señalar que el sector público se convirtió en un importante empleador, recurso de gran valor para las políticas clientelistas del primer Somoza; además, los brazos principales del régimen eran la Guardia Nacional y el Partido Liberal Nacionalista. No obstante, como ya se indicó, las políticas sociales eran secundarias para este Estado intervencionista, cuya prioridad era la promoción de los intereses de las clases propietarias. En resumen, en el centro de las políticas públicas estaba la consolidación del emporio económico de Somoza; esto es lo específico de este Estado y del régimen político que sobre él se edificó. La peculiaridad de este proceso consistió en la fusión de un proyecto de centralización política y militar con el ascenso del poder político, económico y personal de un individuo y su red familiar. Según Walter, el Estado y el régimen somocistas ya se habían consolidado hacia 1950.

Tras más de un siglo de construcción estatal, eran claras las diferencias y desfases entre ambos países. De ese modo, en la época en que Somoza el Viejo se daba a la tarea de fundar el Estado moderno en Nicaragua, en Costa Rica, en el marco de importantes luchas de clases que desembocaron en una corta guerra civil, se trataba de redefinir la naturaleza de su régimen político y las funciones del Estado en la economía y la sociedad. De tales conflictos nació la llamada reforma social, el moderno Estado intervencionista y de bienestar y el actual régimen político democrático. ${ }^{38}$ Después de 1948, hubo en Costa Rica una extensión de las funciones del Estado y una ampliación del sector público (Rovira, 1982). En consecuencia, se incrementó la autonomía relativa del Estado, en claro contraste con la situación de Nicaragua, en la cual el Estado quedó inmerso una red de intereses de una familia dinástica (Ferraro, 2010). ${ }^{39}$

En el caso de Costa Rica, pero también en Nicaragua tras la muerte del fundador de la dinastía, en 1956, hubo un crecimiento cuantitativo y cualitativo del Estado, es decir, hubo un despliegue del Estado, según la expresión de Garavaglia, en términos espaciales o geográficos y en términos de su injerencia en distintos ámbitos de la vida social (Garavaglia, 2007). ${ }^{40}$ Este Estado interventor estimuló el desarrollo capitalista mediante la modernización de los productos tradicionales como el café y la promoción de nuevos sectores como la ganadería y la industria. No obstante, lo peculiar del Estado costarricense fue que a lo largo de este periodo aplicó consistentemente políticas de redistribución, bajo la forma de salarios crecientes y la creación de un salario social, 
expresado en servicios de educación y seguridad social para el conjunto de la población. Por último, la especificidad de Costa Rica no se expresó solo en esta nueva forma de Estado, sino sobre todo en el establecimiento de un régimen democrático efectivo, aunque restrictivo por la prohibición de los comunistas de participar en la competencia electoral.

El nacimiento del Estado intervencionista en Costa Rica se asocia con una ampliación de las élites en el sentido de que la vieja oligarquía cafetalera se vio obligada a compartir el poder con nuevos sectores emergentes y al protagonismo de los sectores medios, tanto los existentes de pequeños y medianos productores rurales, en especial, y urbanos, como de los nuevos creados al calor del Estado intervencionista. En todo caso, es indiscutible que la Costa Rica surgida después de 1950 fue producto de un Estado protagónico que amplió sus funciones y que se desplegó en la mayor parte del tejido social y en casi todo el territorio nacional. En efecto, fue en este periodo cuando se multiplicaron las empresas públicas y las llamadas instituciones autónomas y cuando el Estado costarricense se hizo sentir de manera significativa más allá del Valle Central, es decir, en la provincia de Guanacaste, poco integrada hasta entonces, y en la provincia de Limón, marcada por la experiencia del enclave bananero, desde fines del siglo XIX.

Gracias a procesos electorales transparentes y bastante competitivos, aunque, como se dijo, basados en el supuesto de la exclusión de los comunistas, y a la difusión masiva de las representaciones del excepcionalismo costarricense, la nación se consolidó plenamente y el Estado alcanzó sus más altos niveles de legitimidad. En su última fase, durante el gobierno del socialdemócrata Daniel Oduber, se intentó poner en marcha un capitalismo de Estado, el cual fue desmantelado rápidamente con la llegada de las políticas neoliberales.

Así, como señala Jorge Rovira, la crisis de inicios de la década de 1980 fue la crisis de este estilo de desarrollo adoptado en Costa Rica a lo largo de la década de 1940 y en forma más sistemática y coherente después de 1948 (Rovira, 1987). No obstante, no se puede decir que a partir de esa crisis el Estado costarricense, a pesar de las políticas neoliberales, haya perdido centralidad en el funcionamiento de la sociedad y de la economía. En un balance de los efectos de las políticas neoliberales sobre el sector público costarricense, realizado cuando estaban en su apogeo, se concluyó que durante los PAES I y II no ocurrió una reducción del sector público; esto porque el Estado, además de asumir nuevas funciones para promover las exportaciones, mantuvo los mecanismos de legitimidad y consenso social existentes después de 1948. El gasto social no fue severamente afectado y no se sometió a una política de focalización, aunque sí hubo un deterioro en la calidad y la eficiencia de los servicios, ante una población creciente. Así, el Estado costarricense en la época neoliberal se ha mantenido en tensiones continuas entre las funciones de acumulación y las funciones de legitimación (Castro 48-107). 
El Estado somocista, tras la ejecución de Somoza el Viejo en 1956, se desarrolló también como un Estado intervencionista o desarrollista que amplió sus funciones y se desplegó por el tejido social y por el territorio. No obstante, dicho despliegue se circunscribió al Pacífico nicaragüense y consolidó la condición de la llamada Costa Atlántica como región periférica del Estado nicaragüense. También en términos sociales, el despliegue fue circunscrito porque el somocismo no construyó un Estado de bienestar para el conjunto de la población. Su peculiaridad como fusión de lo público y lo privado se profundizó después de 1956. Lo anterior no obsta para reconocer que la performance del Estado somocista fue muy clara, como lo muestran las cifras de crecimiento del PIB: 1945-1950, $6.3 \%$; 1950, $5.4 \%$; 1960, 6.9 \%; y 1970-1975, $5.6 \%$.

En el periodo 1950-1970, las economías de Nicaragua y Costa Rica tuvieron crecimientos muy notorios. Costa Rica fue líder en América Central en la década de 1950, con una tasa de hasta 7.1 por ciento; mientras que Nicaragua en la década siguiente estuvo a la vanguardia con una tasa de 6.9 por ciento anual. En general, las economías centroamericanas tuvieron tasas de crecimiento más altas que las del resto de América Latina. Evidentemente, el despegue económico de Nicaragua fue impulsado por el desarrollado de las exportaciones: las tradicionales, como café y ganado; y las nuevas, como el algodón y el azúcar. Además, la bonanza permitió un incremento de la recaudación fiscal, la cual en Nicaragua se invirtió en infraestructura, sobre todo, y no en gasto social, como en Costa Rica. Este crecimiento fue posible gracias a un protagonismo estatal promovido por agencias internacionales, pero aceptado por la dictadura. ${ }^{41}$

En conclusión, se puede decir que, con los Somoza, los procesos de construcción estatal, de centralización política, en Nicaragua y Costa Rica, convergieron y la diferencia se cristalizó en la esfera del régimen político y en las modalidades del despliegue del Estado. En fin, el régimen no se puede entender sin la connivencia de las élites no somocistas, las cuales aprendieron a convivir con la dictadura. Como es conocido, después del terremoto de 1972, la dictadura llegó a sus extremos en términos de acaparamiento del poder político y económico y provocó la confluencia entre el descontento de los sectores tradicionales de las élites y el de nuevos sectores medios emergentes. No obstante, quizás, el problema del somocismo es que, por la forma en que construyó el Estado moderno en Nicaragua, sentó las bases para que se reprodujera un fenómeno ya presente en la historia de ese país, es decir, el desmantelamiento del Estado; seguido por un nuevo intento de reconstrucción o refundación estatal, ahora bajo un programa de revolución social.

El Estado de los Somoza también fue destruido porque había sido pieza clave en el sistema de Estados clientes de Estados Unidos en la época de la Guerra Fría. La peculiaridad de este Estado, su total imbricación con el imperio económico de la dinastía, determinó su destrucción. Como dice Knut Walter: "In this respect, the Somoza businesses are more important as a causal explanation of eventual revolution in Nicaragua than 
of the formation of the state" [Los negocios de los Somoza fueron la causa principal de la Revolución de 1979...] (Walter 179).

Durante la Revolución sandinista, el Estado en Nicaragua experimentó un desarrollo inmenso, a diferencia de Costa Rica y en concordancia con su historia de ascenso y retroceso en la construcción estatal. El sector público de Nicaragua sufrió una severa reducción a partir de 1988, ya en tiempos de la Revolución, con una política de estabilización económica, y posteriormente a inicios de la década de 1990, con la aplicación de programas de ajuste estructural. De este modo, como dice Trevor Evans, ocurrió "una dramática reducción del gasto público, una contracción en el empleo estatal, el retiro del Estado de una amplia serie de funciones, y un extenso programa de privatización" (Evans 179).

Según este autor, las políticas de ajuste estructural de inicios de la década de 1990 dejaron un Estado desarticulado, incapaz de promover el desarrollo económico. Además, la reducción del sector público se tradujo en una privatización de los servicios sociales. Se observa, por tanto, una oposición entre un Estado costarricense que no se atreve a abandonar sus funciones de legitimación y un Estado nicaragüense que aplica en forma radical las políticas neoliberales impuestas por el Fondo Monetario Internacional y la Agencia Internacional para el Desarrollo (Evans 179). En fin, habría que reconocer que, aunque hubo una reducción drástica del tamaño y de las funciones del Estado, este conservó, no obstante, su monopolio del uso legítimo de la violencia. En este sentido, en relación con el atributo esencial de la "estatidad", el proceso de formación de Estado resultó irreversible; por lo menos así ha sido en las últimas dos décadas. No obstante, en cierta literatura el Estado nicaragüense es considerado "frágil".

\section{Consideraciones finales}

El octavo capítulo del Cuarto Informe Estado de la Región Centroamericana en Desarrollo Sostenible 2010, "El desafío de los estados de y para la democracia”, presenta un balance de la situación de los aparatos institucionales de la región centroamericana. ${ }^{42}$ El estudio establece dos correlaciones importantes: a menor desarrollo económico, menor tamaño del aparato institucional, a excepción de Panamá; y a mayor desarrollo institucional, mayor desarrollo democrático. En la región los aparatos institucionales son pequeños, poco estructurados, con poco financiamiento y débiles en términos de su penetración en la vida social. Dependen de ejecutivos muy fuertes y están "colonizados" por intereses corporativistas empresariales. Costa Rica se aparta notablemente de esta norma, porque conserva el aparato institucional más grande. En efecto, de las 968 instituciones censadas para toda la región, 276 son de dicho país, es decir, el 28.5 por ciento del total, y concentran el 43.8 por ciento del presupuesto total regional, con lo cual el Estado costarricense es el más grande, más complejo y mejor financiado del istmo. 
En contraste, en Nicaragua se contabilizaron 104 instituciones públicas, es decir, casi 3 veces menos que Costa Rica, con un presupuesto que representaba el 2.9 por ciento del presupuesto total regional, monto ínfimo en relación con el de Costa Rica. Para la fecha del informe, Costa Rica recaudaba prácticamente 5 veces más impuestos que Nicaragua e invertía más de 6 veces en educación y casi 9 veces más en salud. En suma, la diferencia en términos de los niveles de "estatidad" de ambos Estados es abismal y sus consecuencias sobre la calidad de sus regímenes democráticos, manifiestas. ${ }^{43} \mathrm{Tam}-$ bién, en términos de sus regímenes políticos, estos países han vuelto a diferenciarse por el proceso de desmantelamiento progresivo de las instituciones democráticas experimentado por Nicaragua en la última década.

En conclusión, este artículo señala el interés que presentaría investigar, a fondo y en detalle, los procesos de construcción del Estado en Nicaragua, Costa Rica y los otros países centroamericanos. Mientras esta tarea no se realice, los estudios que desde la sociología y las ciencias políticas se hagan sobre los regímenes políticos y las causalidades que a ellos se atribuyen, sea a la manera de Barrington Moore, sea en la forma de factores psicosociales, o bien, en el marco del modelo de path dependence, seguirán pisando un terreno movedizo e inestable. Resulta necesario conocer cuál ha sido la implantación de estos Estados en el territorio supuestamente bajo su control y su vinculación con las poblaciones que lo habitan. Se debe conocer su fiscalidad, su burocracia y sus fuerzas armadas, sus modalidades de articulación de los intereses de las élites y sus formas de producción de dominación y hegemonía en el conjunto de la población. ${ }^{44}$

Si el régimen político es función del proceso de construcción estatal, como se desprende del análisis de O'Donnell y de lo que aquí se ha querido mostrar, es indispensable saber cómo han sido los procesos de state making en Centroamérica desde los tiempos de la independencia. Así, como se ha insistido en este ensayo, el secreto del llamado excepcionalismo costarricense radicaría en la forma en que los procesos de construcción del Estado han ocurrido en esta sociedad en la larga duración. Para utilizar una expresión de Ciska Raventós, Costa Rica se caracteriza por ser una sociedad "estadocéntrica" (Raventós, 2018). ${ }^{45}$ De igual manera, el somocismo, la Revolución sandinista y el régimen político que actualmente impera en Nicaragua solo son inteligibles a la luz de los procesos abortados repetidas veces e inacabados de formación del Estado, a lo largo de los siglos XIX y XX.

\section{Posfacio (2018)}

La primera versión de este trabajo ${ }^{46}$ fue terminada en el año 2013. Hasta la fecha, por distintas circunstancias, no había sido publicado sino hasta ahora, en medio de lo que acontece en Nicaragua. Una vez más este país enfrenta una involución histórica mediante la instauración de un régimen autoritario que ha desmantelado el legado institucional de la Revolución sandinista, el cual a duras penas había sobrevivido hasta 
inicios de este siglo. Lo que había empezado como un proceso de vaciamiento de instituciones, como el régimen electoral, la policía y el ejército, ha terminado en una dictadura familiar sangrienta. También en Costa Rica, el régimen democrático ha pasado por una dura prueba en las pasadas elecciones y el Estado atraviesa un serio periodo de incertidumbre, consecuencia de un grave deterioro de las finanzas públicas, cuya solución aún no se vislumbra, por la desarticulación de las distintas fuerzas políticas y por la resistencia de distintos sectores económicos y sociales. En ambos países, tanto el Estado como su régimen político requieren una profunda renovación. Ciertamente que hay una diferencia, ya que Costa Rica cuenta para reinventarse con un legado institucional; mientras que Nicaragua enfrenta el desafío de liberarse definitivamente de las inercias históricas exploradas en este ensayo.

En el momento actual, ambos países están en una posición diferente en relación con sus procesos de formación de Estado. En Costa Rica se trataría de no desmantelar un acumulado secular y, en Nicaragua, de disolver de manera irreversible una larga tradición sobre la cual se ha erigido el régimen despótico actual. En el primer caso, el fundamento sería la continuidad, mientras que, en el otro, el imperativo sería la ruptura. Claro está que el pasado ni garantiza, ni asegura nada, ya que son las interacciones presentes de sujetos individuales y colectivos las que determinarán los desenlaces, como siempre en todos los procesos históricos, contingentes, no predeterminados.

\section{Notas}

1 Por ejemplo, Deborah J. Yashar. Demanding Democracy. Reform and Revolution in Costa Rica and Guatemala, 1870s-1950s. Stanford, Ca.: Stanford University Press, 1997 y Jeffery M. Paige Coffe and Power. Revolution and the Rise of Democracy in Central America. Cambridge, Mass.: Harvard University Press, 1997. Una preocupación similar preside mi ensayo "Autoritarismo y democracia en Centroamérica: La larga duración -siglos XIX y XX-", publicado en Klaus D. Tangermann. (Comp.) Ilusiones y dilemas de la democracia en Centroamérica. San José: FLACSOBUNSTIFT, 1995. 63-97.

Edelberto Torres-Rivas, desde el Instituto Centroamericano de Administración Pública (ICAP), realizó un trabajo pionero en relación con el estudio de los Estados centroamericanos en una perspectiva histórica. Se puede consultar Edelberto Torres-Rivas y Julio César Pinto. Problemas en la formación del Estado nacional en Centroamérica. San José: ICAP, 1983. Asimismo, Alberto Lanuza et al. Economía y sociedad en la construcción del Estado en Nicaragua. San José: ICAP, 1983. Otro trabajo pionero fue el de Mercedes Muñoz. El Estado y la abolición del ejército, 1914-1949. San José: Editorial Porvenir, 1990.

Un balance de los trabajos realizados en el istmo, inspirados en este autor, se encuentra en Lowell Gudmundson. "Señores y campesinos en la formación de la Centroamérica moderna. La tesis de Barrington Moore y la historia centroamericana", publicado en Arturo Taracena y Jean Piel (Comps.). Identidades nacionales y Estado moderno en Centroamérica. San José, EUCR, 1995.

Sobre la historia entrecruzada, se puede consultar Michael Werner y Bénédicte Zimmermann. "Beyond comparison: histoire croisée and the challenge of reflexivity". History and Theory. 45 (2006): 30-50. Sobre las historias conectadas: Sanjay Subrahmanyam, “Connected histories: 
notes towards a reconfiguration of Early Modern Asia". Modern Asia Studies. 31.3 (1997): 735-762. He intentado desarrollar este enfoque en relación con el proceso de formación de los Estados centroamericanos en el siglo XIX, en el trabajo: "Filibusteros, estados e imperios: Centroamérica (1855-1860)" incluido en mi libro Centroamérica: filibusteros, estados, imperios y memorias. San José: Editorial Costa Rica, 2014. 41-65.

Sobre la vinculación política, administrativa y hacendaria de Costa Rica con Nicaragua, se puede consultar Miles Wortman. Government and Society in Central America, 1680-1840. New York: Columbia University Press, 1982. 224-226.

Sobre los conflictos limítrofes entre estos Estados, se puede consultar Antonio Esgueva. Las fronteras de Nicaragua y Costa Rica en los documentos históricos. Managua: IHNCA-UCA, 2007. Además, Luis Fernando Sibaja y Chester Zelaya. Nicoya: su pasado colonial y su anexión o agregación a Costa Rica. San José: EUNED, 2015.

Sobre la formación de la identidad nacional de Costa Rica, fundada en la idea de excepción y construida a partir de una confrontación sistemática con los otros países centroamericanos y, en especial, con Nicaragua, se puede consultar mi estudio: "La invención de la diferencia costarricense, 1810-1870". Revista de Historia. 45 (2002): 191-228.

También se puede consultar el Programa Estado de la Nación en Desarrollo Humano Sostenible. Cuarto informe Estado de la Región Centroamericana en Desarrollo Humano Sostenible 2010. San José: Estado de la Nación, 2011. 346.

Andrés Pérez en su voluminosa obra, Entre el Estado Conquistador y el Estado Nación. Managua: IHNCA-UCA, 2007, reconstruye la historia del pensamiento político de las élites nicaragüenses, el cual caracteriza como un providencialismo que genera resignación, en el pueblo fatalismo y en las élites una naturalización de la pobreza y el atraso. Este tipo de pensamiento ha condicionado la formación del Estado, el cual define como Estado conquistador, cuyo fundamento es el patrimonialismo y, en el caso de los Somoza, el sultanismo. En su análisis, la cultura y, en específico, el pensamiento político son el factor explicativo del tipo de Estado y de régimen en Nicaragua. De manera similar, el libro de Consuelo Cruz. Political Culture and Institutional Development in Costa Rica and Nicaragua. World Making in the Tropics. New York: Cambridge University Press, 2005, se basa en la idea de que la cultura política opera como un encuadre de los comportamientos de los actores políticos, ya que implica comprensión, afección o sentimiento y valoración y, de ese modo, cumple una función normativa. Un aspecto al cual Cruz pone especial énfasis en la cultura política es la memoria que las élites construyen sobre su pasado compartido. Aquí la noción de memoria se asocia con la identidad nacional, aunque la autora no es totalmente explícita al respecto. Así, una cultura política de negociación enmarca el desarrollo político de Costa Rica, mientras que una cultura política de confrontación enmarca el desarrollo político de Nicaragua. Un correlato de lo anterior es la visión optimista de su historia que tienen los "ticos" y la visión pesimista y fatalista de los "nicas". En este caso, las expectativas determinan los comportamientos políticos. Para Cruz, la nación y la memoria nacional determinan el tipo de régimen político y la misma formación del Estado (Cruz 270). De este modo, la cultura política, como memoria e identidad, funge como la variable independiente que da cuenta de las evoluciones políticas divergentes de ambos países. Se debe advertir que la autora se refiere a la cultura política de las élites, de modo que en su esquema los sectores subalternos no tienen eficacia histórica alguna. Lo más interesante del trabajo de Cruz es identificar la temprana invención del excepcionalismo costarricense en la primera mitad del siglo XIX (92-101). Ahora bien, según mi punto de vista, los "ticos" creen en su excepcionalismo porque ha existido históricamente un Estado que algo o bastante les 
ha dado; aunque es obvia la función integrativa de la identidad nacional, cuando esta cubre a la mayor parte de la población. Por tanto, la clave de la historia de Costa Rica no es la nación con los mitos que transporta, sino el Estado con sus acciones e instituciones que fundan su legitimidad.

Así pensaban tanto los protagonistas de la independencia, como los liberales de la segunda mitad del siglo XIX. Al respecto, se pueden consultar mis trabajos: “La historiografía liberal centroamericana: La obra de Lorenzo Montúfar (1823-1898)". Historia y Sociedad. 12 (2006) y “El liberalismo en Centroamérica en tiempos de la independencia (1810-1850)", publicado en Javier Fernández (Ed.). La aurora de la libertad. Primeros liberalismos en el mundo iberoamericano. Madrid: Marcial Pons Historia, 2012. 117-145.

11 Curiosamente se carece hasta la fecha de un estudio moderno en profundidad de la experiencia histórica de la República Federal Centroamericana; por eso siguen siendo referencia necesaria los siguientes trabajos: Andrés Towsend. Las Provincias Unidas de Centroamérica: Fundación de la República. San José: EDUCA, 1973 y Rodrigo Facio. Trayectoria y crisis de la Federación Centroamericana. San José: Imprenta Nacional, 1949.

Para una crítica del término "anarquía", se puede consultar Justin Wolfe. The Everyday NationState. Community \& Ethnicity in Nineteenth-Century Nicaragua. Lincoln and London: University of Nebraska Press, 2007.

Sobre el problema de la viabilidad de Centroamérica como comunidad política soberana después de la emancipación de España, se puede consultar mi estudio: “Las concepciones de la comunidad política en Centroamérica en tiempos de la Independencia". Trace. 37 (2000), También publicado en Francisco Colom (Ed.), Relatos de la nación. La construcción de las identidades nacionales en el mundo hispánico. Madrid: Iberoamericana, 2005. 251-273. Además, Mario Vázquez. El imperio mexicano y el Reino de Guatemala: Proyecto político y campaña militar, 1821-1823. México: Fondo de Cultura Económica, 2009.

14 Es interesante constatar que el escritor nicaragüense Sergio Ramírez también formula esta idea que denomina "síndrome de la fatiga de las armas":

Nuestras instituciones - nos dice- no han vivido hasta hoy un proceso de evolución creciente, y las guerras civiles han sido una constante desastrosa igual que los terremotos. Hay guerras civiles que cambian el paisaje social al sobrevenir la paz, y ayudan a moldear nuevas instituciones que luego se vuelven inamovibles. Coronel Urtecho solía repetir que los costarricenses, por ejemplo, 'sólo peleaban para no tener que pelear', una frase que no sólo es ingeniosa. La guerra civil de 1948 asentó las bases de la institucionalidad moderna de Costa Rica y trajo consigo la estabilidad. En Nicaragua, las guerras civiles dan la impresión de acarrear un periodo de paz sólo a consecuencia de la extenuación de los bandos en pugna, y siempre quedamos bajo riesgo de regresar otra vez al punto de partida cuando las energías antagónicas se recuperan, igual que la energía sísmica de las entrañas de la tierra (Cruz, p. xxii).

Como se observa en este texto, el procedimiento de comparar Nicaragua con Costa Rica no es inusual entre escritores y científicos sociales nicaragüenses, como ocurre, por ejemplo, con José Coronel Urtecho, Pablo Antonio Cuadra, Arturo y Consuelo Cruz. En esta misma vena de cotejo entre Costa Rica y Nicaragua, conviene consultar Forrest D. Colburn y Arturo Cruz. Varieties of Liberalism in Central America. Nation-States as Works in Progress. Austin: University of Texas Press, 2007. Se trata de un libro más bien periodístico y anecdótico.

15 El papel de Carrillo en el proceso de construcción del Estado en Costa Rica fue ya señalado por Rodolfo Cerdas en su libro La formación del Estado en Costa Rica. San José: Publicaciones 
de la Universidad de Costa Rica, 1967; obra juvenil elaborada en el marco de un marxismo esquemático; no obstante, muy sugerente y pionera en el momento en que fue escrita, a inicios de la década de 1960.

Sobre la centralización política alcanzada por Costa Rica en la década de 1850 durante los gobiernos del presidente Juan Rafael Mora, se puede consultar Carmen María Fallas Santana. Elite, negocios y política en Costa Rica, 1849-1859. Alajuela: Museo Histórico Cultural Juan Santamaría, 2004. Pablo Rodríguez reconstruye los primeros pasos en la evolución del aparato institucional del Estado costarricense en su libro La cuestión fiscal y la formación del Estado en Costa Rica: 1821-1859. San José: EUCR, 2017. Según Oszlak, Costa Rica y Chile fueron los primeros países latinoamericanos en alcanzar la centralización política.

Esta autora reconoce que después de 1844 hubo un intento de "organización de las fuerzas armadas del Estado, financiado mediante un conjunto de nuevas imposiciones fiscales". Pero este intento encontró la resistencia de distintos sectores sociales en los años 1848-1849; por ejemplo, "la resistencia de los poderosos caudillos regionales" quienes se oponían a que el ejército pudiese "cumplir una función pública al servicio del Estado". En suma, a inicios de la década de 1850 el poder central en Nicaragua no podía reclamar para sí el monopolio legítimo de los medios de coerción (169-170).

18 Debe señalarse que la excepción es Arturo Cruz, quien sí reconoce en el gobierno de Fruto Chamorro, un intento fallido de centralización política en Nicaragua. Arturo J. Cruz, Jr. Nicaragua's Conservative Republic, 1858-1893. London: Palgrave, 2002. 38 y 54.

Se puede consultar Acuña, Víctor Hugo. Centroamérica: filibusteros, estados imperios y memorias. Costa Rica: Editorial Costa Rica, 2014.

Sobre el Estado en Guatemala en este periodo, se puede consultar Ralph Lee Woodward. Rafael Carrera and the emergence of the Republic of Guatemala, 1821-1871. Athens: University of Georgia Press, 1993. Véase también el breve ensayo de Edelberto Torres-Rivas, El estado en Guatemala: ¿orden con progreso? Guatemala: PNUD, 2010.

21 Se puede consultar Xiomara Avendaño. “Estado y corporaciones en la Nicaragua del siglo XIX". Independencias, estados y política(s) en la Centroamérica del siglo XIX. Las huellas históricas del bicentenario. Eds. David Díaz y Ronny Viales. San José: CIHAC, 2012. 121-152.

Esta interpretación de la Nicaragua posterior a la independencia en términos de dos mundos autárquicos o de dos "ciudades-estado" en competencia es compartida por varios autores; por ejemplo, E. Bradford Burns. Patriarch and Folk. The Emergence of Nicaragua, 1798-1858. Cambridge, Mass.: Harvard University Press, 1991. Además, las obras ya citadas de Knut Walter y Frances Kinloch.

Según Burns, los dos factores determinantes de los procesos históricos de Nicaragua fueron los patriarcas y el pueblo, es decir, las comunidades agrarias, que gozaban de un amplio acceso a la tierra y que se opusieron a la centralización política y al desarrollo de las relaciones mercantiles en el agro. Los patriarcas por su parte querían un Estado nación moderno y el desarrollo del capitalismo, pero apegados a sus ciudades-estado. Los patriarcas aceptaron la centralización política tras haber derrotado al pueblo en los años 1845-1849 y tras sufrir la experiencia traumática de la usurpación de Walker. También se sintieron interpelados por el desarrollo cafetalero exitoso de Costa Rica. Tras esos eventos se impuso en Nicaragua para el pueblo, lo que el autor llama en otra obra la "pobreza del progreso". Es interesante tomar nota que para Burns la clave para entender la historia de Nicaragua contemporánea se encuentra 
en la primera mitad del siglo XIX y en este sentido se opone a la tesis de James Mahoney sobre las reformas liberales de fines del siglo XIX como punto de partida de un proceso de path dependence en la historia política centroamericana. Se puede consultar: James. Mahoney. The Legacies of Liberalism. Path Dependence and Political Regimes in Central America. Baltimore: John Hopkins Press, 2001. Este estudio da por supuesto la existencia del Estado, ya que su problema es el régimen político. En este sentido, para nuestros propósitos su utilidad es limitada. Además, su modelo depende de un conocimiento incompleto de las historiografías centroamericanas y parece ajustar los datos en forma un tanto ad hoc; por ejemplo, en el caso de Costa Rica, cuyo tránsito hacia el desarrollo cafetalero ocurrió casi medio siglo antes que en los otros países del istmo. Conviene recordar que el primero en usar la noción de path dependence para el caso centroamericano fue Robert G. Williams. En mi análisis coincido con Burns en el sentido de localizar en el periodo anterior a la guerra contra los filibusteros el momento clave de la divergencia en la larga duración en términos de los procesos de construcción estatal e invención nacional entre Costa Rica y Nicaragua.

Este erudito y voluminoso estudio que reconstruye la historia política de Nicaragua, desde la perspectiva de los procesos electorales, por medio de la transcripción parcial o total de documentos, es muy ilustrativo del carácter abortivo de los procesos de construcción estatal en este país. Es interesante observar que aún en ausencia de un proceso de centralización del poder político y de institucionalización del régimen político se celebraban elecciones con regularidad. Al respecto se puede consultar: Hugo Vargas. “La formación del Estado en Nicaragua: entre el sufragio y la violencia (1821-1854)". Independencias, estados y política(s) en la Centroamérica del siglo XIX. Las huellas históricas del bicentenario. Eds. David Díaz y Ronny Viales. San José: CIHAC, 2012. 153-195.

Esta es mi interpretación del proceso de invención nacional en Costa Rica, la cual no es compartida por otros autores que la sitúan en la época liberal. Al respecto se puede consultar: Palmer, Steven. A Liberal Discipline: Inventing Nations in Guatemala and Costa Rica, 1870 - 1900. Columbia University Ph. D. Thesis, 1990. Además, "Getting to know the unknown soldier: official nationalism in liberal Costa Rica, 1880-1900". Journal of Latin American Studies. 25. 1 (1993): 45-72.

Me refiero a los ya citados Edward Burns, Arturo Cruz, Justin Wolfe y Knut Walter. También la idea forma parte de un consenso general dentro de la historiografía nicaragüense.

Debe indicarse que Arturo Cruz y Knut Walter se remiten a este trabajo cuando se refieren al Estado en la época de los llamados Treinta Años.

Se puede consultar Cruz, Arturo. Nicaragua's Conservative Republic, 1858-1893. London: Palgrave, 2002. Según nos recuerda este autor, es interesante señalar que en esta época Nicaragua fue llamada la "Suiza de Centroamérica".

Sobre la noción de Estados-clientes, se puede consultar John H. Coatsworth. Central America and the United States. The Clients and the Colossus. New York: Twayne Publishers, 1994.

Sobre el régimen de José Santos Zelaya, es posible consultar: Benjamin I. Teplitz. The political and economic foundations of modernization in Nicaragua: The administration of José Santos Zelaya 1893-1909. (Howard University Ph. D. Thesis, 1973). Ann Arbor, Michigan: Xerox University Microfilms, 1974. Este trabajo muestra que lo que caracteriza a este régimen es la centralización del poder político en el sentido del establecimiento de una dictadura, pero evidentemente este no es su enfoque. También deja claro que Zelaya puso el Estado al servicio del desarrollo 
agroexportador y que sometió a la Iglesia y al poder municipal. También se puede consultar Cruz, Arturo. Nicaragua's Conservative Republic, 1858-1893. London: Palgrave, 2002.

31 Para una síntesis de la historia política de Costa Rica en este periodo, se puede consultar: Orlando Salazar. El apogeo de la república liberal en Costa Rica. San José: EUCR, 1997.

Puede consultarse mi trabajo Los orígenes de la clase obrera en Costa Rica: las huelgas de 1920 por la jornada de ocho horas. San José: CENAP-CEPAS, 1986.

Véase al respecto: Steven Palmer e Iván Molina. Educando a Costa Rica: alfabetización popular, formación docente y género (1880-1950). San José: Editorial Porvenir, 2000 y Steven Palmer. From popular medicine to medical populism: doctors, healers and public power in Costa Rica, 1800-1940. Durham, NC/ London: Duke University Press, 2003.

Estudio de excepcional calidad que permite reconstruir la evolución de la fiscalidad de Costa Rica a lo largo de ese periodo dominado por el régimen liberal. También se puede consultar Robert G. Williams. States and Social Evolution. Coffe and the Rise of National Governments in Central America. Chapell Hill and London: University of North Carolina Press, 1994. Para este autor: "By the end of the nineteenth Century, the Costa Rican state expended its resources in a much more balanced fashion between military, public education and provision of infrastructure (Fomento) than was true elsewhere in the region" (231).

Al respecto, se puede consultar el clásico ensayo de Rodrigo Facio. Estudio sobre economía costarricense. San José: Editorial Costa Rica, 1972.

El análisis que se presenta sobre el régimen de los Somoza se basa esencialmente en el excelente estudio ya citado de Knut Walter The regime of Anastasio Somoza... En lo que se refiere al proceso de construcción estatal en particular, se puede consultar el Capítulo 3.

Este estudio es muy útil para conocer la expansión algodonera en el Pacífico de Centroamérica en las décadas de 1950, 1960 y 1970. Desde 1953 y hasta 1976 Nicaragua fue el principal productor y el principal exportador de algodón de la región (Cuadro A-1, p. 197 y Cuadro A-2, p. 198). También desde 1960 y hasta 1979 fue el principal exportador de carne del istmo, seguido por Costa Rica (Cuadro A-10, p. 206).

La bibliografía de la guerra civil de 1948 en Costa Rica es muy abundante. Sin duda, su nuevo punto de partida es el excelente estudio de David Díaz Crisis social y memorias en lucha: guerra civil en Costa Rica, 1940-1948. San José: EUCR, 2015.

Este extenso libro se ocupa del régimen de los Somoza, pero no propiamente del Estado que construyeron. Lo poco que dice al respecto remite al estudio de Knut Walter. Lo más interesante del trabajo es el análisis que hace de las propiedades y bienes de la dinastía.

En esta obra el autor utiliza la idea de "despliegue del Estado" como la extensión de sus funciones en distintas áreas de la vida social. Este despliegue puede ser cualitativo en sentido de la aparición de nuevas áreas de competencia estatal, como cuantitativo, en el sentido de que los funcionarios y los recursos del Estado se incrementan. Garavaglia no lo dice explícitamente, pero el despliegue del Estado ocurre también en términos espaciales, es decir, como incremento de su presencia en el territorio.

41 Se puede consultar Victor Bulmer-Thomas. The Political Economy of Central America since 1920. Cambridge: Cambridge University Press, 1987; en particular el apéndice estadístico (307-337). 
Además, Roser Solá. Un siglo y medio de economía nicaragüense: las raíces del presente. Managua: IHNCA-UCA, 2007, específicamente el Capítulo 2 (29-46).

También se puede consultar Jorge Vargas. (En prensa). El Leviatán concebido: ensayo preliminar sobre la conformación del Estado en Costa Rica. San José: CIAPA, 2012.

La relación entre niveles de "estatidad" y calidad de la democracia es reconocida en el trabajo de Fabrice Lehoucq. The Politics of Modern Central America. Civil War, Democratization and Underdevelopment. New York: Cambridge University Press, 2012.

El Programa Estado de la Nación de Costa Rica ha puesto en marcha una investigación histórica sobre las instituciones de los Estados centroamericanos. Un primer producto de este estudio ha sido un análisis comparado de Nicaragua y Costa Rica, realizado en colaboración con el Instituto de Historia de Nicaragua Centroamérica (IHNCA) de la UCA-Managua. Se puede consultar Pablo Rodríguez y Ludwing Moncada. “'Base de datos sobre instituciones públicas de Costa Rica y Nicaragua, 1840-1940'. Una propuesta para el análisis comparativo de Centroamérica". Anuario de Estudios Centroamericanos. 43 (2017): 347-371.

Esta matriz "estadocéntrica" fue clave en la lucha contra la aprobación del Tratado de Libre Comercio impuesto por Estados Unidos a Centroamérica y República Dominicana hace una década. Aquí el excepcionalismo costarricense se manifestó en forma de un fuerte rechazo a la imposición imperial, en claro contraste con los otros países firmantes, incluido Nicaragua.

Trabajo realizado en el marco del proyecto Elites, States and Reconfigurations of Power in Central America, 1990-2011 del Center for Latin American and Latino Studies (CLALS), American University, finalizado en 2013.

\section{Bibliografía}

Acuña, Víctor Hugo. “Autoritarismo y democracia en Centroamérica: La larga duración -siglos XIX y XX-". Ilusiones y dilemas de la democracia en Centroamérica. Comp. Tangermann, Klaus D. San José: FLACSO-BUNSTIFT, 1995. 63-97.

Acuña, Víctor Hugo. “El liberalismo en Centroamérica en tiempos de la independencia (18101850)". La aurora de la libertad. Primeros liberalismos en el mundo iberoamericano. Ed. Javier Fernández. Madrid: Marcial Pons Historia, 2012. 117-145.

Acuña, Víctor Hugo. “Filibusteros, estados e imperios: Centroamérica (1855-1860)". Centroamérica: filibusteros, estados, imperios y memorias. San José: Editorial Costa Rica, 2014. 41-65.

Acuña, Víctor Hugo. “La historiografía liberal centroamericana: La obra de Lorenzo Montúfar (1823-1898)". Historia y Sociedad, 12 (2006): 29-59. Recuperado de https://revistas.unal. edu.co/index.php/hisysoc/article/view/20429

Acuña, Víctor Hugo. “La invención de la diferencia costarricense, 1810-1870”. Revista de Historia, 45 (2002): 191-228.

Acuña, Víctor Hugo. “Las concepciones de la comunidad política en Centroamérica en tiempos de la Independencia". Trace (CEMCA). 37 (2000): 27-40.

Acuña, Víctor Hugo. Los orígenes de la clase obrera en Costa Rica: Las huelgas de 1920 por la jornada de ocho horas. San José: CENAP-CEPAS, 1986.

Acuña, Víctor Hugo y Molina, Iván. Historia económica y social de Costa Rica (1750-1950). San José: Editorial Porvenir, 1991. 
Avendaño, Xiomara. "Estado y corporaciones en la Nicaragua del siglo XIX". Independencias, estados y política(s) en la Centroamérica del siglo XIX. Las huellas históricas del bicentenario. Eds. David Díaz y Ronny Viales. San José: CIHAC, 2012. 121-152.

Bulmer-Thomas, Victor. The Political Economy of Central America since 1920. Cambridge: Cambridge University Press, 1987.

Burns, E. Bradford. Patriarch and Folk. The Emergence of Nicaragua, 1798-1858. Cambridge, Mass.: Harvard University Press, 1991.

Castro, Carlos. "Sector público y ajuste estructural en Costa Rica (1983-1992)”. La transformación neoliberal del sector público. Ajuste estructural y sector público en Centroamérica y el Caribe. Coord. Trevor Evans. Managua: CRIES, 1995. 48-107.

Cerdas, Rodolfo. La formación del Estado en Costa Rica. San José: Publicaciones de la Universidad de Costa Rica, 1967.

Coatsworth, John H. Central America and the United States. The Clients and the Colossus. New York: Twayne Publishers, 1994.

Colburn, Forrest D. y Cruz, Arturo. Varieties of Liberalism in Central America. Nation-States as Works in Progress. Austin: University of Texas Press, 2007.

Cruz, Arturo. Nicaragua's Conservative Republic, 1858-1893. London: Palgrave, 2002.

Cruz, Consuelo. Political Culture and Institutional Development in Costa Rica and Nicaragua. World Making in the Tropics. New York: Cambridge University Press, 2005.

Díaz, David. Crisis social y memorias en lucha: guerra civil en Costa Rica, 1940-1948. San José: EUCR, 2015.

Esgueva, Antonio. Elecciones, reelecciones y conflictos en Nicaragua (1821-1963). Managua: IHNCA-UCA, 2011.

Esgueva, Antonio. Las fronteras de Nicaragua y Costa Rica en los documentos históricos. Managua: IHNCA-UCA, 2007.

Evans, Trevor. "Ajuste estructural y sector público en Nicaragua". La transformación neoliberal del sector público. Ajuste estructural y sector público en Centroamérica y el Caribe. Managua: CRIES, 1995.

Facio, Rodrigo. Estudio sobre economía costarricense. San José: Editorial Costa Rica, 1972.

Facio, Rodrigo. Trayectoria y crisis de la Federación Centroamericana. San José: Imprenta Nacional, 1949.

Fallas Santana, Carmen María. Elite, negocios y política en Costa Rica, 1849-1859. Alajuela: Museo Histórico Cultural Juan Santamaría, 2004.

Ferraro, María Dolores. La Nicaragua de los Somoza, 1936-1979. Huelva: Universidad de Huelva, 2010.

Garavaglia, Juan Carlos. Construir el estado, inventar la nación. El Río de la Plata, siglos XVIII-XIX. Buenos Aires: Prometeo Libros, 2007.

Gobat, Michel. Confronting the American Dream. Nicaragua Under U.S. Imperial Rule. Durham, NC.: Duke University Press, 2005.

Gobat, Michel. Empire by Invitation. William Walker and Manifest Destiny in Central America. Cambridge, Mass.: Harvard University Press, 2018.

Gould, Jeffrey L. Orgullo amargo. El desarrollo del movimiento obrero nicaragüense (1912-1950). Managua: IHNCA-UCA, 1997.

Gudmundson, Lowell. “Señores y campesinos en la formación de la Centroamérica moderna. La tesis de Barrington Moore y la historia centroamericana". Identidades nacionales y 
Estado moderno en Centroamérica. Comp. Arturo Taracena y Jean Piel. San José: EUCR, 1995. 31-41.

Guerra, François-Xavier. "The Spanish-American tradition of representation and its European roots". Journal of Latin American Studies, 26.1 (1994): 1-3.

Guerra, François-Xavier. Modernidad e Independencias. Ensayos sobre las revoluciones hispánicas. México: Fondo de Cultura Económica, 1993.

Kinloch, Frances. El imaginario del canal y la nación cosmopolita. Nicaragua, siglo XIX. Managua: IHNCA-UCA, 2015.

Lanuza, Alberto. "La formación del Estado nacional en Nicaragua: Las bases económicas, comerciales y financieras entre 1821 y 1873". Economía y sociedad en la construcción del Estado en Nicaragua. Eds. Alberto Lanuza et al. San José: ICAP, 1983. 7-138.

Lehoucq, Fabrice. The Politics of Modern Central America. Civil War, Democratization and Underdevelopment. New York: Cambridge University Press, 2012.

Lehoucq, Fabrice y Molina, Iván. Stuffing the ballot box. Fraud, electoral reform and democratization in Costa Rica. Cambridge: Cambridge University Press, 2002.

Mahoney, James. The Legacies of Liberalism. Path Dependence and Political Regimes in Central America. Baltimore: John Hopkins Press, 2001.

Moore, Barrington. Social Origins of Dictatorship and Democracy: Lord and Peasant in the Making of the Modern World. Boston: Beacon Press, 1966.

Muñoz, Mercedes. El Estado y la abolición del ejército, 1914-1949. San José: Editorial Porvenir, 1990.

Obregón, Clotilde. Carrillo: una época y un hombre, 1835-1842. San José: Editorial Costa Rica, 1991.

O’Donnell, Guillermo. Acerca del Estado en América Latina Contemporánea. Diez tesis para la discusión. DRALC-PNUD, 2003.

Oszlak, Oscar. “El Estado democrático en América Latina. Hacia el desarrollo de líneas de investigación". Nueva Sociedad. 210 (2007): 42-63.

Oszlak, Oscar. "The historical formation of the state in Latin America: Some theoretical and methodological guidelines for its study". Latin American Research Review, 16.2 (1981): 3-32.

Paige, Jeffery M. Coffee and Power. Revolution and the Rise of Democracy in Central America. Cambridge, Mass.: Harvard University Press, 1997.

Palmer, Steven. A Liberal Discipline: Inventing Nations in Guatemala and Costa Rica, 1870 - 1900. Columbia University Ph. D. Thesis, 1990.

Palmer, Steven. "Getting to know the unknown soldier: official nationalism in liberal Costa Rica, 1880-1900". Journal of Latin American Studies. 25.1 (1993): 45-72.

Palmer, Steven. From popular medicine to medical populism: doctors, healers and public power in Costa Rica, 1800-1940. Durham, NC/ London: Duke University Press, 2003.

Palmer, Steven y Molina, Iván. Educando a Costa Rica: alfabetización popular, formación docente y género (1880-1950). San José: Editorial Porvenir, 2000.

Pérez, Andrés. Entre el Estado Conquistador y el Estado Nación. Managua: IHNCA-UCA, 2007.

Pérez Brignoli, Héctor. "The Economies Central America, 1860-1940". An Economic History of Twentieth-Century Latin America (Vol. 1). The Export Age: The Latin American Economies in the Late Nineteenth and Early Twentieth Centuries. Eds. Enrique Cárdenas, José Ocampo Antonio y Rosemary Thorp. London y New York: Palgrave, 2000. 85-118. 
Programa Estado de la Nación en Desarrollo Humano Sostenible. Cuarto informe Estado de la Región Centroamericana en Desarrollo Humano Sostenible 2010. San José: Estado de la Nación, 2011.

Ramírez, Sergio. "Prólogo, Recuerdos de Arcadia". La República Conservadora de Nicaragua, 1858-1893. Ed. Arturo Cruz. Managua: Colección Cultural de Centroamérica, 2003. xxi-xxxv.

Raventós, Ciska. Mi corazón dice NO. El movimiento de oposición al TLC en Costa Rica. San José: EUCR, 2018.

Rodríguez, Mario. The Cádiz Experiment in Central America, 1808-1826. Berkeley: University Press, 1978.

Rodríguez, Pablo. La cuestión fiscal y la formación del Estado en Costa Rica: 1821-1859. San José: EUCR, 2017.

Rodríguez, Pablo y Moncada, Ludwing. “'Base de datos sobre instituciones públicas de Costa Rica y Nicaragua, 1840-1940'. Una propuesta para el análisis comparativo de Centroamérica". Anuario de Estudios Centroamericanos. 43 (2017): 347-371.

Román, Ana Cecilia. Las finanzas públicas de Costa Rica: metodología y fuentes (1870-1948). San José: CIHAC-UCR, 1995.

Rovira, Jorge. Costa Rica en los años'80. San José: Editorial Porvenir, 1987.

Rovira, Jorge. Estado y política económica en Costa Rica. San José: Editorial Porvenir, 1982.

Salazar, Orlando. El apogeo de la república liberal en Costa Rica. San José: EUCR, 1997.

Sibaja, Luis Fernando y Zelaya, Chester. Nicoya: su pasado colonial y su anexión o agregación a Costa Rica. San José: EUNED, 2015.

Solá, Roser. Un siglo y medio de economía nicaragüense: las raíces del presente. Managua: IHNCAUCA, 2007.

Subrahmanyam, Sanjay. "Connected histories: notes towards a reconfiguration of Early Modern Asia". Modern Asia Studies. 31.3 (1997): 735-762.

Taracena, Arturo y Piel, Jean. Comps. Identidades nacionales y Estado moderno en Centroamérica. San José: EUCR, 1995.

Teplitz, Benjamin I. The political and economic foundations of modernization in Nicaragua: The administration of José Santos Zelaya 1893-1909 (Tesis doctoral). Ann Arbor, Michigan: Xerox University Microfilms, 1974.

Torres-Rivas, Edelberto. El estado en Guatemala: ¿orden con progreso? Guatemala: PNUD, 2010.

Torres-Rivas, Edelberto. Interpretación del desarrollo social centroamericano. San José: EDUCA, 1973.

Torres-Rivas, Edelberto y Pinto, Julio César. Problemas en la formación del Estado nacional en Centroamérica. San José: ICAP, 1983.

Towsend, Andrés. Las Provincias Unidas de Centroamérica: Fundación de la República. San José: EDUCA, (Segunda edición), 1973.

Vargas, Hugo. "La formación del Estado en Nicaragua: entre el sufragio y la violencia (18211854)". Independencias, estados y politica(s) en la Centroamérica del siglo XIX. Las huellas históricas del bicentenario. Eds. David Díaz y Ronny Viales. San José: CIHAC, 2012. 153-195.

Vargas, Jorge. (En prensa). El Leviatán concebido: Ensayo preliminar sobre la conformación del Estado en Costa Rica. San José: CIAPA, 2012.

Vázquez, Mario. El Imperio mexicano y el Reino de Guatemala: Proyecto político y campaña militar, 1821-1823. México: Fondo de Cultura Económica, 2009. 
Velázquez, José Luis. La formación del Estado en Nicaragua, 1860-1930. Managua: Fondo Editorial Banco Central de Nicaragua, 1992.

Walter, Knut. The regime of Anastasio Somoza, 1936-1956. Chapel Hill: University of North Carlina Press, 1993.

Walter, Knut. "El somocismo: Del protectorado a la revolución". Encuentros con la historia. Ed. Margarita Vannini. Managua: IHN-UCA, 1995. 329-360.

Werner, Michael y Zimmermann, Bénédicte. "Beyond comparison: histoire croisée and the challenge of reflexivity". History and Theory. 45 (2006): 30-50.

Williams, Robert G. Export Agriculture and the Crisis in Central America. Chapel Hill: University of North Carolina Press, 1986.

Williams, Robert G. States and Social Evolution. Coffee and the Rise of National Governments in Central America. Chapell Hill y London: University of North Carolina Press, 1994.

Wolfe, Justin. The Everyday Nation-State. Community \& Ethnicity in Nineteenth-Century Nicaragua. Lincoln: University of Nebraska Press, 2007.

Woodward, Ralph Lee. Rafael Carrera and the emergence of the Republic of Guatemala, 1821-1871. Athens: University of Georgia Press, 1993.

Wortman, Miles. Government and Society in Central America, 1680-1840. New York: Columbia University Press, 1982.

Yashar, Deborah J. Demanding Democracy. Reform and Revolution in Costa Rica and Guatemala, 1870s-1950s. Stanford, Ca.: Stanford University Press, 1997.

Víctor H. Acuña Ortega. Costarricense. Doctor en Historia (1978) de la Escuela de Altos Estudios en Ciencias Sociales de París, Catedrático y Profesor Emérito de la Universidad de Costa Rica. Ha sido profesor e investigador invitado en universidades de Alemania, Inglaterra, Francia, España, Estados Unidos, México, Colombia y Centroamérica. Recibió el Premio Nacional de Historia de Costa Rica en 1993 y las Palmas Académicas de la República de Francia en 2003. Ha publicado diversos trabajos sobre historia económica, social, política y cultural de Costa Rica y Centroamérica en los siglos XVIII-XX.

Contacto: vhacuna@gmail.com

ORCID: 0000-0002-4901-7407 
